short book title 
some publisher notes ... 
Book title

Editors 
Publisher:

ISBN: 


\section{Table of Contents}

Preface

vii

1 Весоме and its Presuppositions

Manfred Bierwisch 



\section{Preface}

In hindsight, the debate about presupposition following Frege's discovery that the referential function of names and definite descriptions depended on the fulfillment of an existence and a uniqueness condition was curiously limited for a very long time. On the one hand, it was only in the 1960s that linguists began to take an interest and showed that presupposition was an allpervasive phenomenon far beyond this philosophers' pet definite descriptions. And on the other hand, and this is our real concern, it is now only too obvious that the uniqueness condition is too restrictive to be applicable to the general case. An utterance of "The cat is on the mat" should not imply that there is only one cat and one mat in the whole world. The obvious move is to limit the uniqueness condition to some notion of utterance context.

Theories of context-dependent propositions began to sprout in the 1970s (with Gazdar, Karttunen, and Stalnaker as the main protagonists), but a full-fledged notion of a context which evolves not only as we go through a sequence of sentences, but also while we analyze the internal structure of sentences, was only available with the advent of dynamic semantics. Dynamic semantics came into being through the need to account for anaphoric reference. But before long, van der Sandt showed that the problem of linking the pronoun to a suitable antecedent was but a variant of the all-embracing problem of presupposition projection.

So it is hardly a decade ago that presupposition theory has been cast into a promising theoretical form. And as this provided an inspiring starting point for further research, we thought that, at the turn of the century, the time had come to discuss what the new theory had taught us and which promising further perspectives had been opened up. This was the motivation behind the conference on "Presupposition" which we convened in Stuttgart in October 2000, and which gave rise to the papers collected in this volume. The conference was funded by the Deutsche Forschungsgemeinschaft, which we gratefully acknowledge.

Undoubtedly, presupposition theory is a major chapter in the success story of dynamic semantics. A conference on the topic thus also seemed to us the ideal birthday present for one of the founding fathers of dynamic semantics, our teacher and friend Hans Kamp, on his 60th birth-day. To him we dedicate the volume as an expression of our gratitude for his untiring effort to make us understand.

RB, Th.E.Z. and UR

Stuttgart, July 2006 



\title{
BECOME and its Presuppositions
}

\author{
Manfred Bierwisch, \\ Institut für deutsche Sprache und Linguistik, \\ Humboldt University Berlin \\ mb@german.hu-berlin.de
}

\section{Opening}

In spite of continuous debate over the appropriate characterization of various details, there is little doubt that the semantic component frequently represented as BECOME is a crucial element in the structure of natural language. Standard examples illustrating the pertinent phenomena are minimal pairs like those in (1) and (2), differing by the presence of BECOME in (b) where (a) just lacks it:

a. Eve is an actress.

The crew slept.

The shop is open.

Some of the kids were sick.

(2)

a. Hans schlief. (Hans slept)

Eva schwieg. (Eva was silent)

Max ist wach. (Max is awake)

Er ist Buddhist. (He is a Buddhist) b. Eve becomes an actress.

The crew fell asleep.

The shop opens.

Some of the kids got sick.

b. Hans schlief ein. (Hans fell asleep)

Eva verstummte. (Eva became silent)

Max erwacht. (Max wakes up)

Er wird Buddhist. (He becomes a Buddhist)

There are various diagnostics and criteria identifying the relevant properties, e.g. with respect to the temporal structure. Thus usually the (a)-cases allow for durational adverbials, but not the (b)-cases. The present paper will focus on another, well-known aspect, viz. the presupposition introduced by the occurrence of BECOME, according to which e.g. Eva verstummte presupposes that she spoke before, while no such requirement comes with Eva was silent. 
In what follows, I will briefly recapitulate the standard analysis of BECOME, turning then to some of the peculiarities related to its presuppositional aspect. A number of more complex phenomena will then be considered on the basis of this discussion.

\section{Standard Assumptions}

The most obvious function of BECOME is to characterize so called inchoative verbs like die, get up, or the examples in (1.b) and (2.b), including the corresponding causative verbs like kill, denoting the causation of an event expressed by an inchoative verb. ${ }^{1}$ These change-of-state verbs (or 2state verbs in the sense of Klein (1994)) denote the transition from a source state $\mathrm{s}$ to a target state $\mathrm{s}^{\prime}$. The basic assumptions taking care of these conditions have been formulated e.g. in Dowty (1979) by means of the operator BECOME as indicated in (3), where $\phi$ is the target-state and I, J, K are time intervals, schematically indicated in (4):

$[\operatorname{BECOME} \phi]$ is true at $\mathrm{I}$ if and only if

(i). there is an interval $\mathbf{J}$ containing the initial bound of I such that $\neg \phi$ is true at $\mathbf{J}$, and

(ii). there is an interval $\mathrm{K}$ containing the final bound of I such that $\phi$ is true at $\mathrm{K}$.

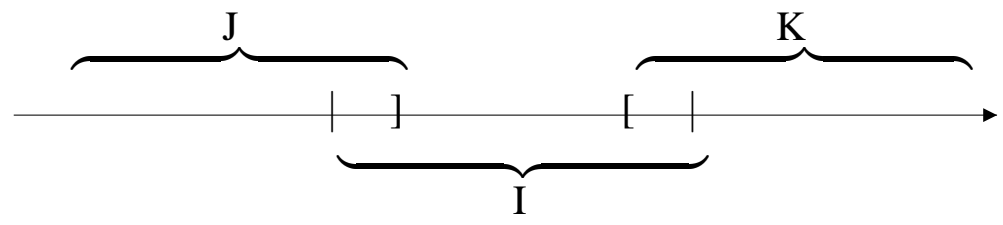

There are two problems to be clarified with respect to this account. First, as it stands, I may extend over arbitrary parts of the source as well as the target state, such that The cat died could apply to a situation that includes arbitrary parts of the cat's lifetime and/or arbitrary periods of the cat's not being alive anymore. For this reason, Dowty contemplates the extension of (3) by a condition (iii) that there is no interval $\mathrm{I}^{\prime}$ that meets condition (i) and (ii), i.e. I must be the smallest interval that includes the bound of $\mathrm{J}$ and $\mathrm{K}$. Dowty does not suggest to adopt condition (iii) though, because it leads to difficulties in view of the second problem to be clarified, which has to do with the interval $\mathrm{I}^{\prime \prime}$ between the source and the target state. If one relies on strictly two-valued logic, no interval $\mathrm{I}^{\prime \prime}$ between $\mathrm{J}$ and $\mathrm{K}$ is possible, as either $\phi$ or $\neg \phi$ must hold - there is no transition. Together with condition (iii), any change of state would be strictly momentary. The solution Dowty suggests with respect to these two problems is, first to discard condition (iii) in favor of some sort of Gricean maxim, which picks out a short, but non-empty interval appropriate under conditions of encyclopedic or common sense knowledge, and second to acknowledge intervening time-

1 It might be noted that in many cases, English inchoative verbs and their corresponding causatives are homophonous (giving rise to the somewhat misleading term "ergative verb"), differing, however by the presence of the causative factor and the pertinent argument - as in He opened the shop vs. The shop opened. I will have to return to this issue below, noting for the time being, however, that the relevant distinctions and relations carry over from inchoatives to their causative counterparts. 
intervals with undecided (or non-two-valued) truth conditions. ${ }^{2}$ On this account, verbs like die or leave are correctly construed as specifying neither the duration of nor the properties holding at the interval between the initial state $\neg \phi$ and the target state $\phi$, nor exactly when $\neg \phi$ and $\phi$ begin or end. As a matter of fact, what is fixed by an utterance like (5) is merely the transition (at some time before the utterance and at the same day) from Bill's being at some contextually given location to his not being there, without any specification whether this took place by walking or driving, by bike or by plane, whether it was a rapid or slow event, etc:

Bill left today.

Using notational conventions of an event-based semantics with events e and states s as sorts of eventualities in the sense of Bach (1986), the Semantic Form of (5) could thus be represented as in (6), where $\mathrm{T}(\mathrm{e})$ and $\mathrm{T}(\mathrm{u})$ indicate the time of the event and the time of utterance, respectively, and $\mathrm{v}$ is a contextually specified place parameter:

$$
\exists e[[\underbrace{T(e)<T(u)}_{\mid \text {Past } \mid}] \wedge[\underbrace{T(e) \subset D A Y \wedge T(u) \subset D A Y}_{\mid \text {today } \mid}] \wedge e:[\underbrace{B E C O M E \neg[L O C[\text { Bill AT v }]]}_{\mid \text {Bill leave v } \mid}]]
$$

In the sense of definition (3), the actual event e, instantiating the proposition |Bill leave $\mathrm{v} \mid$ could be characterized as in (7), where $\bigcirc$ indicates temporal overlap mentioned before:

(7) If e, s, and $\mathrm{s}^{\prime}$ are eventualities with $\mathrm{T}(\mathrm{e})=\mathrm{I}, \mathrm{T}(\mathrm{s})=\mathrm{J}, \mathrm{T}\left(\mathrm{s}^{\prime}\right)=\mathrm{K}$, where $\mathrm{T}(\mathrm{e}) \bigcirc \mathrm{T}(\mathrm{s}), \mathrm{T}(\mathrm{e})$

$\bigcirc \mathrm{T}\left(\mathrm{s}^{\prime}\right)$ and $\mathrm{T}(\mathrm{s})<\mathrm{T}\left(\mathrm{s}^{\prime}\right)$, then Bill leave denotes an event e such that:

$$
e:[\underbrace{s: L O C:[\text { Bill AT v }]}_{\text {source state }}) \wedge \underbrace{s^{\prime}: \neg[L O C:[\text { Bill AT v }]]}_{\text {target state }}
$$

This leads to the following general consequences:

(i) A change of state or BECOME-event e need (and frequently does) not have any other characterization than that given by its bounds. In other words, the nature of the transition determined by BECOME is characterized exclusively by the boundaries it connects. Verbs like leave, get, arrive, die do in fact provide no other specification of the transition between two states.

(ii) There is, moreover, no specification of the time interval I' between the boundaries of $\mathrm{T}(\mathrm{s})$ and $\mathrm{T}\left(\mathrm{s}^{\prime}\right)$. $\mathrm{I}^{\prime}$ might be empty, as in instantaneous transitions like the atom lost a particle, or it may have substantial extension as in the towel got dry where for a certain time span I' the towel is not dry, but not as wet as before either: It is just not defined.

2 As Dowty shows, the choice of intervals can be made sufficiently precise by means of an intervalsemantics, which I need not pursue here, as the details of time structure are not my primary concern. The undecided truth-value of the interval between $\neg \phi$ and $\phi$ need not concern us here either, as it is the status of I rather than $\mathrm{I}^{\prime \prime}$, that we have to deal with. 
(iii) The specification of the transition by means of its boundaries noted in (i) is in fact restricted to the target state, the source state being completely derivable as the negation of the target state. ${ }^{3}$ (Since the target state in (7) is a negated state itself, the source state must, of course, be a positive condition.) Hence the defining information in a BECOME-event is the specification of the target state.

While these generalizations can be read off more or less directly from the characterization in (3) and the illustration in (7), the following observations bring in additional facts:

(iv) The restrictions noted in (i) and (iii) must not be construed as excluding substantial specification of the transition - or even as denying the transition as the very core of the BECOME-event. There are in fact verbs that characteristically specify the transition in various ways. German verbs of dying like ertrinken (be drowned), ersticken (choke), verhungern (starve), verdursten (die with thirst) illustrate the point, to which I will return from a different perspective. What is to be noted here is the fact that qualifications of this sort are not due to the change-of-state conditions expressed by BECOME.

(v) It is furthermore well known that the transition identified by BECOME can be subject to temporal localization and delimitation, as in (8) and (9), but not - with two qualifications to be discussed immediately - to durational qualification, as shown in (10):

(8) a. The shop opened at noon.

b. Das Geschäft öffnete um zwölf.

(9) a. The cat died in/within two hours.

b. Die Katze starb in/innerhalb von zwei Stunden.

(10) a. *The cat died (for) two hours.

b. *Die Katze ist zwei Stunden (lang) ertrunken.

(vi) The different status of source and target state noted in (ii) has further aspects, one of which is directly related to the qualifications just mentioned: Durative adverbials combining with change of state verbs, as in (11) and (12), can be accommodated by shifting the specification they express from the event to the target state:

(11) a. The shop closed for two hours.

b. Der Laden hat zwei Stunden geschlossen.

(12) a. Eve came to London for some days.

b. Eve kam (für) einige Tage nach London.

${ }^{3}$ Apparent counterexamples like melt, where the source state is more specific than just the negation of the target state will be taken up below. 
Cases like (11) cannot be interpreted as denoting a process of two hours, nor, of course, a source state of two hours, but only as determining the duration of the resulting state. This emphasizes its prominence mentioned in (iii) from another perspective.

Before I get to the main aspect of the asymmetry to be pursued here, I will mention the other qualification hinted at in $(\mathrm{v})$, which takes care of durative adverbials modifying change of state verbs in cases like (13) and (14):

(13) a. For several hours, visitors entered the hall.

b. Mehrere Stunden lang betraten Besucher das Haus.

(14) a. Captives broke out of this prison for quite a while.

b. Die ganze Zeit sind Häftlinge aus diesem Gefängnis ausgebrochen.

Here the durative adverbial applies to a process that is made up by the iterated change, induced, among other things, by the plurality of the Theme. We will have to return to this problem as we proceed. For the time being, it should be noted that the durative adverbial does not specify the change of state per se, determined by BЕCOME, but either its result or a kind of process constituted by its repetition.

To sum up the main points of the received analysis: Change-of-state- or BECOME-events necessarily involve a source state $s$, a target state $s^{\prime}$, and a transition e, where s precedes $s^{\prime}$ and is contained in the complement of $\mathrm{s}^{\prime}$, and e overlaps with $\mathrm{s}$ and $\mathrm{s}^{\prime}$. The substantial information of the change of state is given by the specification of the target state $s^{\prime}$.

\section{Assertion, Presupposition, and Implication}

Turning now to the presuppositional aspect of BECOME, we notice a three-way distinction between e, s, and s' in (7) - or equivalently I, J, and K in (4) - in terms of assertion (or more generally: condition), presupposition (or precondition) ${ }^{4}$, and implication (or consequence). Evidence for this claim comes from the usual criteria, to be reviewed briefly.

First, the presuppositional character of the initial or source state can be seen from the fact that asserting, denying, or questioning the transition all require the source state to be met, as illustrated in (15)(a) to (c), all of which presuppose that Bill was in his office before:

\footnotetext{
4 A terminological remark might be in place. The phenomena usually lumped together as presuppositions have been treated under various perspectives. A systematic account has been developed a. o. in Karttunen and Peters (1979), where "conventional implicature" is used instead of "presupposition". To the extent that this is more than just a terminological difference, I will be concerned here with presupposition in the sense more recently discussed e.g. in Kamp (2001) and the references given there. In what follows, I will also adopt notational conventions to represent presuppositions proposed in Kamp (2001).
} 
(15) a. Bill left his office.

b. Bill didn't leave his office.

c. Did Bill leave his office?

The presupposition in question is supposed to hold also if the question (c) is negated by (b). It can only be suspended by an explicit denial, usually called "presupposition protest", as in (16)(a), while (16)(b) is out, as it explicitly violates the conditions for a change of state:

(16) a. Bill didn't leave his office, as he wasn't in at all.

b. \#Bill left his office, but he wasn't in at all.

Second, the resulting or target state is a (necessary) consequence, implied by the transition, as indicated by the contradiction in (17)(a). But it does not imply a transition, just as the presupposition does not require a change to take place. In other words, the target state may hold, even if no previous change takes place, as borne out by the acceptability of (17)(b):

(17) a. \#Bill left his office, but he was not out of it afterwards.

b. Bill was not in his office, in fact he was out all day (hence he didn't leave it).

Finally, the condition proper, the change from source to target, is satisfied if and only if the presupposition, the consequence, and the transition hold. In other words, if either the presupposition or the consequence is not met, no change is possible and the condition fails, as (16)(b) and (17)(a) show. The negation of the change, on the other hand, is true if the consequence is false, while the presupposition holds - according to default conditions. In other words, the negation of BECOME is equivalent to the assertion that the source state persists. Hence (18)(a) holds if and only if (18b) holds:

(18) a. Bill didn't leave his office this morning.

b. Bill remained in his office this morning.

If, on the other hand, by way of presupposition protest the source state is negated, the negation of the change can only be true if the target state holds without relevant change - the normal interpretation of (16)(a). In other words, the absence of a change requires either the source or the target state to persist, the former being the default case that can be switched to the second only by means of (explicit or implicit) presupposition protest.

According to standard definition, a proposition $\phi$ presupposes $\psi$, if and only if $\phi$ implies $\psi$ and $\neg \phi$ also implies $\psi$. In order to account for the observations just discussed, we might provisionally modify the definition in the way indicated in (19):

$\phi$ presupposes $\psi=_{\text {def }} \phi$ is true only if $\psi$ is true and $\neg \phi$ is true only if $\psi$ is true, except $\psi$ is explicitly rejected. 
With this proviso, the asymmetry between the presupposed source state and the implied target state can be accommodated by the following modification of (3):

$[\operatorname{BECOME} \phi]$ is true at I if and only if

(i) there is an interval $\mathrm{K}$ containing the final bound of I with $\phi$ implied to be true at $\mathrm{K}$,

(ii) there is an interval J containing the initial bound of I with $\neg \phi$ presupposed to hold at J.

This characterization has obvious consequences for the information to be specified for lexical entries as well as other constructions involving BECOME: Once the target state is determined, the presupposed source state is automatically defined and need therefore not be specified as lexical information. In other words, while lexically induced presuppositions must somehow be specified as a characteristic property of e. g. factive verbs like grasp or regret (as opposed to non-factive verbs like claim or $a s s u m e)^{5}$ or particles like too, also ${ }^{6}$, and again $^{7}$, the presupposition induced by the inchoativity of verbs like come, leave, enter, die, open etc. are fully predictable and need not lexically be indicated. The same holds for causative verbs such as bring, kill, or transitive open specifying the causation of a change of state: In order to bring about the change in question, the source state to be changed must be met in the first place. For the same reason, resultative constructions like (21)(a) are automatically associated with a presupposed source state indicated by $(21)(b)$, which is not a presupposition of its parts, as can be seen from (21)(c) and (d):

(21) a. Max wiped the table clean (\#although it was clean).

b. The table was not clean.

c. Max wiped the table (although it was clean).

d. The table was clean (\#and it was not clean).

If no additional conditions interfere, wipe is just an activity without particular presuppositions or specified result. And the adjective clean does not make any presupposition either. ${ }^{8}$ The causative

5 The presuppositional character of factive verbs has first been observed by Kiparsky and Kiparsky (1970) and was subsequently discussed in a large number of different approaches. The point to be noted here is the fact that it is a matter of idiosyncratic, lexical information whether a factive presupposition is associated with a given verb or not, while no such idiosyncracy holds for the initial state of an inchaotive verb.

${ }^{6}$ See Reis and Rosengren (1997) for a recent survey of the pertinent facts. Even though the paper is primarily concerned with the problem of how the particle determines its focus, it necessarily deals implicitly with the lexical basis of the presupposition the particle induces.

7 There is an extensive discussion about this particle, summarized e.g. in Dowty (1979), Kamp and Roßdeutscher (1994), von Stechow (1996), which focuses, however, on the scope assigned to the particle, from which the presupposition it induces is then derived. - I will take up one aspect of this particle in Section 7 below.

${ }^{8}$ For adjectives, the role of presuppositions is in general less obvious and more controversial than for verbs. Thus whether e.g. a type crossings like red idea exemplifies a presupposition violation of the adjective, which requires reference to a physical object, might be a matter of dispute. In any case, presuppositions of adjectives are not excluded in principle, and elements like silent are naturally construed as presupposing animacy. On this background, it isn't just a triviality that clean has no presupposition, as it applies to physical objects, processes, or even abstract entities like clean measures. 
verb clean on the other hand, appearing e.g. in Max cleaned the table does, of course, automatically induce the presupposition indicated in (21)(b), due to the component BECOME it contains. The way in which causative verbs like clean and resultative constructions like wipe clean acquire the semantic components CAUSE and BECOME with their interpretive consequences is systematically discussed in Wunderlich (2000) and Bierwisch (2002).

In order to spell out the presuppositional aspect of BECOME more explicitly, including related elements with their consequences, some remarks on notational conventions seem to be in order.

\section{Lexical Representation of Presuppositions}

In Kamp (2001), a systematic distinction is made between representation, computation and justification of presuppositions. To begin with, an explicit account of their representation is needed, which then allows to clarify the computation of presuppositions, i.e. the way in which they arise on the basis of lexical information and compositional semantics. The justification of a presupposition is then concerned with the problem of how it is either satisfied within the given context, or how the context is to be modified in order to accommodate the presuppositional requirement. According to a revealing observation developed in van der Sandt (1992) and adopted in Kamp (2001), justification of a presupposition by previous or inferred conditions is in essential respects identical to the relation of anaphoric elements to their antecedent. In this section, I will sketch minimal assumptions about the representation of lexical presuppositions, which in turn requires a general format for the representation of lexical information. I will then turn to the computation of presuppositions as far as they depend on BECOME and related elements.

To begin with, we have to recognize that a lexical entry E must provide at least three types of information: First an array of phonetic features determining the contribution of $E$ to the Phonetic Form PF of the expressions it occurs in; second a complex structure representing the Semantic Form SF of E determining the contribution of $\mathrm{E}$ to the semantic interpretation (or meaning) of the expressions it occurs in; and third a specification of the Grammatical Form GF defining the combinatorial requirements that guarantee the correspondence between PF and SF for complex expressions build up from E. More Specifically, GF has two components sometimes called Categorization Cat and Subcategorization or Argument Structure AS, where Cat is a structured set of morpho-syntactic features defining the grammatical properties of E as a head, while AS specifies the requirements E imposes on its co-constituents. Each of these components and their interaction can be elaborated in various ways. For obvious reasons, I have little to say here about PF. As to Cat, I will rely on familiar conventions about morphological and lexical categorization by means of binary features. The representation of AS and SF is based on standard assumptions about type systems with lambda abstraction. More specifically, SF is a functor-argument-structure made up from constants and variables, where variables are bound, substituted, or interpreted according to conditions of formal or semantic and situational context, while constants are subject to (more or less invariant) conceptual interpretation ${ }^{9}$. Of particular interest in the present context is the

9 To make this interpretation explicit is an extremely complex and ramified task that has to cope with rather different types of problems that can only occasionally be touched here. One type of interpretation, however, is indicated by the treatment of the functor BECOME in (20). 
binding of variables by lambda-abstractors that constitute Argument Positions in AS, relating the variables in question to the conditions imposed by the complements a lexical head combines with. To that effect, Argument Positions are usually associated with morpho-syntactic features defining requirements on the categorization of the constituent that is to saturate the position. ${ }^{10}$ Thus AS participates in the morpho-syntactic as well as the semantic information of $\mathrm{E}$ and constitutes in a way the interface between its syntactic and semantic structure. A simplified example illustrating the ingredients just mentioned would be the entry (22) for the adjective open:

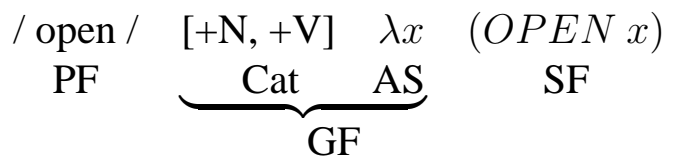

The one-place predicate OPEN is to be understood as a short-hand for a fairly complex condition representing free access or passage to or by the argument represented by the variable $\mathrm{x}$. This variable, bound by the entry's only Argument Position $\lambda \mathrm{x}$, is to be specified either by the subject of a copulative construction with open as its predicate (as in the window was open) or by the head noun of an attributive construction with open as its modifier (as in an open window).

We get closer to issues specifically related to our present interests, if we consider entries that account for open as an inchoative and as a causative verb, related of course to the adjective just discussed. The pertinent entries are given in (23)(a) and (b), respectively:
a. / open / $[+\mathrm{V},-\mathrm{N}]$
$\lambda \mathrm{x} \lambda \mathrm{e}[\mathrm{e}:[$ BECOME [OPEN $\mathrm{x}]]]$
b. / open /
$[+\mathrm{V},-\mathrm{N}]$
$\lambda \mathbf{x} \lambda \mathbf{y} \lambda \mathrm{e}[\mathrm{e}:[[\operatorname{ACT} \mathrm{y}][$ CAUSE [BECOME [OPEN $\mathrm{x}]]]]]$

A number of comments are in place here. First, within SF a variable "e" for eventualities is assumed, which is then - along the lines familiar from DRT-representations - associated with a proposition it instantiates, by the colon ":". Formally, then, the colon is a relational operator that turns a proposition and an individual into a proposition ${ }^{11}$. Second, the event variable just mentioned is bound by the position " $\lambda \mathrm{e}$ " in $\mathrm{AS}$, which differs from other argument positions in

${ }^{10}$ The most familiar conditions in this respect are Case features distinguishing subject, direct and oblique object. Other conditions identify finite and infinite complement clauses, or various types of predicates of copulative constructions. There are important generalizations controlling this aspect of AS, which I cannot pursue here. For a more systematic exposition of these matters, which are not in the focus of the present discussion, see e.g. Bierwisch (1997), Wunderlich (2000), and references given there.

${ }^{11}$ In Bierwisch (1997) and elsewhere I have used an operator INST indicating the instantiation of a proposition by an eventuality in much the same way. An alternative proposal with ultimately the same effect is made in Wunderlich (1997), where CAUSE, BECOME (and various other semantic elements) are treated as propositional operators that are relativized to eventualities, incorporating, in a way, the effect of the colon represented here as a separate operator. - The term "eventuality" is used in the sense proposed by Bach (1986), covering both events and states. Notationally, I will adopt the widespread practice using "e" as a variable for eventualities in general, and "s" as a variable to mark states, whenever the distinction is relevant. It should be noted however, that the logical type of eventualities covers events as well as states and processes as sortal distinctions within the same type. 
systematic ways, essentially due to the categorization of verbs by the feature combination $[+\mathrm{V}$, $-\mathrm{N}]$ in Cat. In other words, reference to eventualities, syntactically anchored in a particular argument position, is a category-specific property of verbs. The role of this event position is directly related to the clause-specific functional categories $\mathrm{T}$ (ense) and $\mathrm{C}$ (omplementizer) in ways that must be left aside for the moment ${ }^{12}$. Third, the ordering of lambda-operators in AS, i.e. the hierarchy of syntactic argument positions, is - at least by default - a direct consequence of the position the pertinent variable occupies in SF: earlier, that is lower ranking, argument positions are bound to more deeply embedded variables in SF. For details see e.g. Bierwisch (1997). Finally, given entries like (22) and (23), the well-known relatedness between the adjective and the two verbs open, and more generally the relation between adjectives and corresponding causative and inchoative verbs can be captured in at least two ways. One is to collapse the related entries, using their similarities to reduce the lexical information. I will illustrate this option in two steps. The first step is to integrate the inchoative and the causative verb into one entry that represents two options, depending on the choice of the parts enclosed in heavy parentheses:

$$
\text { lopen/ } \quad[+\mathrm{V},-\mathrm{N}] \quad \lambda \mathrm{x}\left({ }_{\beta} \lambda \mathrm{y}\right) \lambda \mathrm{e}\left[\mathrm{e}:\left[\left(_{\beta}[\mathrm{ACT} \mathrm{y}][\text { CAUSE) }[\text { BECOME }[\text { OPEN x }]]]\right]\right]\right.
$$

The subscripts of the parentheses indicate that the enclosed parts are either both present or absent. The second step uses the same conventions to integrate (24) with the simple adjective (22), which comes out as the residue if the content of $(\alpha \ldots)$ is deleted ${ }^{13}$ :

$$
\text { lopen/ } \left.\quad[+\mathrm{V},-\alpha \mathrm{N}] \quad \lambda \mathrm{x}\left({ }_{\alpha}\left({ }_{\beta} \lambda \mathrm{y}\right) \lambda \mathrm{e}\left[\mathrm{e}:\left[{ }_{\beta}[\mathrm{ACT} \mathrm{y}][\mathrm{CAUSE})[\text { BECOME })[\text { OPEN x }]\right]\right]\right]\right]
$$

The alternative way to capture the relationship between (22) and (23) is to stick to the simple lexical entry (22) for the adjective, generating the pertinent inchoative and causative verbs by two more general templates (26)(a) and (b), which yield (23)(a) and (b), respectively, if applied to $(22)$, such that the variable "P" is substituted by OPEN:

$$
\begin{array}{llll}
\text { a. } & / \varnothing / & {[+\mathrm{V},-\mathrm{N}]} & \lambda \mathrm{P} \lambda \mathrm{x} \lambda \mathrm{e}[\mathrm{e}:[\operatorname{BECOME}[\mathrm{P} \mathrm{x}]]] \\
\text { b. } & / \varnothing / & {[+\mathrm{V},-\mathrm{N}]} & \lambda \mathrm{P} \lambda \mathrm{x} \lambda \mathrm{y} \lambda \mathrm{e}[\mathrm{e}:[[\text { ACT } \mathrm{y}][\text { CAUSE [BECOME [P x]]]]] }
\end{array}
$$

We will notice below that (26)(a) is a phonologically empty variant of the inchoative copula $b e$ come, and (26)(b) is a kind of empty variant of make or cause to be. One of the problems created

12 Different, but converging proposals by Higginbotham (1985), Bierwisch and Lang (1989), Kamp and Reyle (1983), Kratzer (1994), Wunderlich (1997), Kamp (2000), to mention just a few, have integrated the verbal event reference with various aspects of argument structure, tense, adverbial modification.

13 In (25), the subscript $\alpha$ of the parentheses is construed as a variable over + and -, where " + " indicates the presence and "-" the absence of the content. These values are then also used to relate the content of SF and AS to the features in Cat, such that $+\mathrm{N}$ shows up, if $\alpha$ is -, hence the content of the parentheses empty, and $-\mathrm{N}$ otherwise. These notational devices have been proposed in Chomsky and Halle (1968), in order to express generalizations in phonological rules. It has since been argued that this use of value-variables allows all sorts of spurious or even absurd generalizations, such that it has been discarded in phonology. Similar objections seem to hold with respect to lexical information. Hence the proposal formulated in (25) is presumably to be discarded in favor for (26). See Bierwisch (1997) for some discussion of the problem. 
by (26) depends on the lexical constraints, idiosyncratically delimiting the set of adjectives to which these templates apply: while both (26)(a) and (b) apply e.g. to open, dry, clear, near, narrow, only causativization by (26b) holds for clean or wet, and neither applies to long, short, red and many other adjectives. ${ }^{14}$ It might be added, by the way, that (26)(b) is very similar to a template that incorporates adjectives not into causative verbs, but rather into resultative constructions like he pushed the door open, where the matrix verb specifies the activity indicated by ACT in (26)(b). ${ }^{15}$

With this sketch of lexical information in mind, I will now turn to the question how the representation of presuppositions will enter the picture. The general orientation I will follow in this respect is given by the proposals developed in Kamp (2001). According to these proposals, which I will adopt as far as lexical information is concerned, the semantic representation of a linguistic expression consists of at least two parts, the descriptive part $\mathcal{D}$ and the presupposition $\mathcal{P}$, for which I will use the following notation:

$[\{\mathcal{P}\} \mathcal{D}]$ where $\mathcal{D}$ consists of the Semantic Form SF as discussed so far, and $\mathcal{P}$ a (possibly empty) set of conditions based on the same elements as SF.

We will have to add further comments, as we proceed. ${ }^{16}$ The two parts of the lexical entries are then subject to compositional integration into the representation of complex expressions. For $\mathcal{D}$ the compositional integration is essentially a consequence of saturating the positions in AS by way of functional application (followed by lambda conversion) in one of two ways: If it is the AS of a syntactic head, its positions are saturated by the appropriate complements; if it is the AS of a modifier or adjunct, its designated Argument position is unified with a position in the AS of the head it modifies. As to the presupposition $\mathcal{P}$, the conditions it contains are integrated into the presuppositional part $\mathcal{P}^{\prime}$ of the constituent it enters by syntactic composition. This integration

14 Causative formation as characterized by (26)(b) does in fact apply to long, short or strong, but not by means of phonetically vacuous templates: lengthen, shorten, strengthen introduce the suffix -en, in addition to previous nominalization in the case of long and strong. Proposals concerning the intricate interaction of derivational suffixes and the lexical items they select are discussed in Bierwisch (1990).

15 More technically, the resultative template proposed by Wunderlich (2000) would look as follows:

(i) $/ \varnothing /[+\mathrm{V},-\mathrm{N}] \lambda \mathrm{P} \lambda \mathrm{x} \lambda \mathrm{V} \lambda \mathrm{y} \lambda \mathrm{e}\left[\mathrm{e}:\left[\left[\mathrm{V} \mathrm{y} \mathrm{e}^{\prime}\right]\right.\right.$ [CAUSe [BeCOME [P x]]]]]

Without going into the details of distinguishing strong and weak resultative constructions discussed in Wunderlich (2000), I will merely point out that BECOME enters this construction with all relevant consequences in rather similar ways as it shows up in causatives derived by word formation.

16 In Kamp (2001) and related work, the descriptive part as well as the conditions in the presupposition are represented in DRS-format. Although the conversion between the SF- and DRS-format is in practically all respects straightforward, I will stick here to the SF-representation as summarized in Bierwisch (1997) for two interrelated reasons: First, while a DRS is constituted by an essentially unstructured set of propositions, SF combines constants and variables according to their types into an integrated hierarchy. For reasons discussed in Bierwisch (1997), this hierarchy corresponds to a strictly binary branching structure. Second, the hierarchy of positions in the Argument Structure AS, which relates variables in SF to syntactic constituents specifying their value, depends crucially on just the SF-structure in question. There is no problem to impose this type of structure on the set of propositions of a DRS, but then we arrive at the SF organization adopted here. 
involves either local justification, if a condition in $\mathcal{P}$ is met by the compositionally derived SF, or it is unified with the conditions coming from its sister constituents. ${ }^{17}$

Let me illustrate the consequences of (27) by a simple example. The inchoative verb melt, for which we might assume, in analogy to the entry (23)(a) for open, an entry like (28) as a first approximation, is a somewhat special case in several respects.

$$
/ \mathrm{melt} / \quad[+\mathrm{V},-\mathrm{N}] \quad \lambda \mathrm{x} \lambda \mathrm{e}[\mathrm{e}:[\text { BECOME [LIQUID } \mathrm{x}]]]
$$

First, the change of state denoted by melt may (and usually does) involve a fairly extended period between the presupposed and the target state. Moreover, this intermediate period is not just undefined with respect to its properties, as in e.g. die, open, or disappear. It rather is a clear state of liquidity of part of the melting object. Nevertheless, melt is clearly a change of state, as borne out by (29):

$$
\text { My ice cream melted }\{\text { (within) in a few minutes / ? for half an hour }\}
$$

It is not essential for the moment whether melt should therefore be classified as an achievement or an accomplishment in the standard sense. Second, and that is the crucial point at the moment, melt does not simply denote the transition from non-liquid to liquid, as required from a standard inchoative verb, but more specifically from solid to liquid. Let us suppose that this more specific condition is to be represented as in (30), giving rise to the lexical presupposition as indicated:

$$
\text { /melt/ }
$$

$$
[+\mathrm{V},-\mathrm{N}]
$$
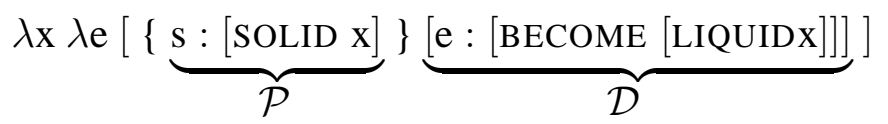

In other words, the event e of x's becoming liquid presupposes a state s of x's being solid. Notice that " $x$ " is bound by the argument position " $\lambda \mathrm{x}$ " in both the presupposition and the descriptive part. This is clearly not sufficient, though. In order to specify the relevant presupposition the state s must meet the condition discussed in (7) above, i.e. it must overlap the event e (and precede the target state $s^{\prime}$ ). Suppose we consider the temporal relation of e and $s^{\prime}$ as part of the conditions associated with the constant BECOME that might be expressed as in (31):

$$
\text { (e: [Become } \mathrm{p} \text { ] is true at } \mathrm{t} \text { ) implies }\left(\mathrm{s}^{\prime}:[\mathrm{p}] \text { is true at some } \mathrm{t}^{\prime} \text { with } \mathrm{t}^{\prime} \bigcirc \mathrm{t}, \mathrm{t}^{\prime} \bigcirc \mathrm{t}^{\prime \prime}, \mathrm{t}<\mathrm{t}^{\prime \prime}\right) \text {. }
$$

In other words, the target state $\mathrm{s}^{\prime}$ overlaps with e, but also with some $\mathrm{t}^{\prime \prime}$ after e, hence $\mathrm{s}^{\prime}$ must include the final part of e. (31) at the same time guarantees that the truth of the target state $\mathrm{p}$ is implied by the change. With this general condition on BECOME in mind, we might complete the entry for melt as in (32), where, 's $\bigcirc \mathrm{e}$ ' is short for ' $\mathrm{T}(\mathrm{s}) \bigcirc \mathrm{T}(\mathrm{e})$ ':

17 This is an extremely provisional description of what happens to $\mathcal{D}$ and $\mathcal{P}$ in the construction of complex expressions. Some of the additional requirements to be observed will be filled in as we proceed. For a slightly more detailed exposition of the saturation of positions in AS see Bierwisch (1997) and references given there. A by far more scrutinized account of the compositional construction of presuppositions is developed in Kamp (2001), where also additional distinctions within $\mathcal{P}$ are made, to which I have to return. 


$$
/ \mathrm{melt} / \quad[+\mathrm{V},-\mathrm{N}] \quad \lambda \mathrm{x} \lambda \mathrm{e}[\{\mathrm{s} \bigcirc \mathrm{e} \& \mathrm{~s}:[\operatorname{SOLID} \mathrm{x}]\}[\mathrm{e}:[\text { BeCOME [LiQuid } \mathrm{x}]]]]
$$

As the state characterized by [LIQUID $\mathrm{x}$ ] overlaps with the end of e, [SOLID $\mathrm{x}$ ] can only precede it, if it is still to overlap e. Notice that both e and $\mathrm{x}$ in the presuppositional part are bound by the respective argument positions. Hence whatever happens to these variables in SF will also apply to their occurrence in the presuppositional part. There are two further problems to be noted. First, the properties identified by SOLID and LIQUID must be construed as relying on what might be called common sense physics, specifying general knowledge about aggregate states of familiar substances, including the possible transitions. Hence the fact that heat is involved in liquefying solid substances might be considered as supplied by encyclopedic knowledge activated by the transition in question. Otherwise, an additional condition which specifies the increase of temperature of $\mathrm{x}$ must be added to the target state. Second, as it stands, the transition from solid to liquid applies to the object $\mathrm{x}$ as a whole - contrary to fact, as already noted. It might in fact be part of the common sense knowledge just mentioned that a change of aggregate state applies to the substance, rather than shape or function of objects, turning them automatically into mass objects, such that the change gets partitioned according to the continuous or mass character of the object relative to the change of aggregate state $^{18}$. Instead of adding further complications to (32), the main purpose of which was simply to illustrate the representation of lexical presuppositions, I will leave it at that, returning to the issue under a different perspective below.

One final point is to be made here. The presupposition in (32) introduces the variable "s", which does not occur in SF, but it does not constitute a discourse referent to be taken up elsewhere. Therefore no particular care must be taken of this implicit variable. The more general case, however, needs the representation and binding of discourse referents. Kamp (2001) elaborates the standard assumptions about discourse referents in important ways, providing in particular an additional component $\mathrm{BC}$ of Binding Conditions providing the different options and restrictions according to which the referential variables of nominal and verbal constituents exert their referential capacity. I will try to avoid these complexities as far as possible, focusing on the problem of computing lexical presuppositions.

\section{Computing the Presupposition of BЕсомE}

As already noted, melt differs from inchoative verbs in general, as its presupposed state is more specific than just the negation of the target state. In the general case, however, the presupposed source state is fully predictable. The overall strategy of restricting lexical entries to the idiosyncratic information would therefore require the computation of the predictable presuppositions by

18 There are at least two options to be considered here, if the issue is not shifted from semantics to extralinguistic common sense knowledge. One is to represent the 'grinding' of the object and the correspondingly emerging sub-events explicitly in the lexical information, such that (32) would have to be replaced by something like (i):

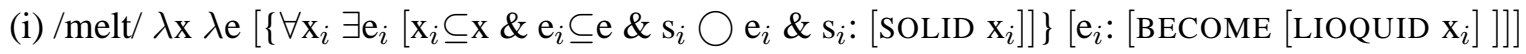

The other option would be to rely on a general template that as a kind of "universal grinder" accounts for the fact that in (ii) the ice cube is treated as a substance rather than a cube by turning (32) into something like (i). 
general principles or at least language specific templates that apply across the board.

Given the discussion of (32) and the general observations about BECOME, it is obvious what for an inchoative verb like open the result of this computation should look like: The entry (23)(a) repeated here as (33)(a) - must be expanded into (33b):
a. lopen/ $[+\mathrm{V},-\mathrm{N}]$
$\lambda \mathrm{x} \lambda \mathrm{e}[\mathrm{e}:[$ BECOME [OPEN x]]]
b. /open/ $[+\mathrm{V},-\mathrm{N}]$
$\lambda \mathrm{x} \lambda \mathrm{e}[\{\mathrm{s} \bigcirc$ e \& s: $\neg[$ OPEN x] $\}$ [e: [BECOME [OPEN x]]]]

It is just a notational task to formulate an operation that would have this effect:

$$
[\mathrm{e}:[\operatorname{BECOME}[\mathrm{p}]]] \Rightarrow[\{\mathrm{s} \bigcirc \mathrm{e} \& \mathrm{~s}: \neg[\mathrm{p}]\}[\mathrm{e}:[\text { BECOME }[\mathrm{p}]]]]
$$

Instead of postulating an operation that expands the left into the right hand side of (34), which would then require to somehow block iteration, it seems more appropriate to consider (34) as a constraint on well-formed lexical entries, which supplies the presupposition if an entry that meets the left hand side enters the derivation of an actual expression. Taken together, this constraint and the condition (31) would then provide the full interpretation of BECOME.

With this proviso, standard inchoative verbs like open, die, disappear etc. can be lexically represented in the simple form without presupposition, as in (33)(a) or (35):

$$
\text { /disappear/ } \quad[+\mathrm{V},-\mathrm{N}] \quad(\lambda \mathrm{y}) \lambda \mathrm{x} \lambda \mathrm{e}[\mathrm{e}:[\text { BeCOME }[\neg[\text { PRESENT AT } \mathrm{y}] \mathrm{x}]]]]
$$

Two remarks are to be added here. First, the target state is characterized by a negated condition. Hence the constraint (34) will supply - as its negation - a positive condition. Second, the condition of the target state specifies the absence of the theme $\mathrm{x}$ from some location $\mathrm{y}$, which may be left completely implicit, however. This possibility is indicated by the optional argument position binding the variable in question. If the location is made explicit, though, it appears as a directional PP, as in (36). This is provisionally indicated by associating the optional position " $\lambda y$ " with the morpho-syntactic feature $[+\operatorname{Dir}] .{ }^{19}$

(36) a. The target will disappear (from the screen).

b. The snow disappeared (from most places).

Obviously, the assumptions discussed so far must hold also with respect to what might be called the inchoative copula, i.e. the verb that merely adds the change-of-state operator to the predicative of the copula. Examples like (37) illustrate the point:

19 This is only a provisional hint. The actual problem to be faced here both syntactically and semantically are rather complex and must be left aside here. Notice however, that the value of "y", whether explicitly or implicitly specified, figures in both the target state and the presupposition. 

a. His brother was famous.
b. His brother became famous.
The book will be a scandal. The book will become a scandal.
She is an excellent teacher.
Mary was sick.
She becomes an excellent teacher.
They were there in time.
Mary got sick.
They got there in time.

There are nontrivial conditions distinguishing the use of become and get, which I must ignore here, treating become as the canonical case, which essentially provides BECOME with the accessories of a fully fledged lexical entry: ${ }^{20}$

$$
\text { /become/ } \quad[+\mathrm{V},-\mathrm{N}] \quad \lambda \mathrm{P} \lambda \mathrm{x} \lambda \mathrm{e}[\mathrm{e}:[\operatorname{BECOME}[\mathrm{P} x]]]
$$

The feature $[+\mathrm{N}]$ associated with the argument position " $\lambda \mathrm{P}$ " is a provisional way to indicate the selectional conditions for the predicative that combines with become. I assume here, that $\lambda \mathrm{P}$ must be saturated by a nominal constituent, i.e. an adjective as in become pregnant, or a noun as in become president. For the sake of illustration, suppose that (39) is a simplified entry for the adjective famous, which (38), completed according to the constraint (34), combines with to form the VP become famous, represented in (40): ${ }^{21}$

$$
\text { /famous/ } \quad[+\mathrm{N},+\mathrm{V}] \quad \lambda \mathrm{z}[\text { FAmous } \mathrm{z}]
$$

$$
\begin{aligned}
& \text { /become famous/ }[+\mathrm{V},-\mathrm{N}] \\
& \lambda \mathrm{x} \lambda \mathrm{e}[\{\mathrm{s} \bigcirc \mathrm{e} \wedge \mathrm{s}: \neg[\text { FAMOUs } \mathrm{x}]\}[\mathrm{e}:[\text { BeCOME [FAmous } \mathrm{x}]]]]
\end{aligned}
$$

I want next like to show how these assumptions can account for what might be considered as the dual counterpart of become, preferably realized by the verb remain. The correspondence between the inchoative copula and its counterpart may be illustrated by (41)(a) and (b), which have almost identical meanings, provided ill is construed as equivalent to not healthy: ${ }^{22}$

20 This is not the place to deal with the remarkable complexity of the various readings of get, only one of which is a close relative of become. I would nevertheless like to hint at the obvious similarity that the relation between causative and inchoative get shares with that between transitive and intransitive open, melt, dry, etc. In other words, the relation between constructions like (i) and (ii) should be treated parallel to the two verbs open represented in (24). Hence, either by means of the Causative template or as a complex lexical entry, we would have two readings of get as indicated in (iii):

(i) He got things right ( He opened the shop)

(ii) Things got right $(\sim$ The shop opened)

(iii) /get/ $[+\mathrm{V},-\mathrm{N}] \lambda \mathrm{P} \lambda \mathrm{x}\left({ }_{\beta} \lambda \mathrm{y}\right) \lambda \mathrm{e}\left[\mathrm{e}:\left[\left({ }_{\beta}[\right.\right.\right.$ ACT $\mathrm{y}][$ CAUSE) [BECOME $\left.\left.\left.[\mathrm{P} \mathrm{x}]]\right]\right]\right]$

For discussion of related properties of get see Haegeman (1985).

21 More explicitly, (40) derives in three steps. Supplying first (38) with the presupposition by means of (34) gives (i), which then combines with (39), yielding (ii), where by lambda conversion " $\lambda \mathrm{P}$ " is deleted and "P" replaced by " $\lambda \mathrm{z}$ [ FAMOUS z ]". Finally, lambda conversion turns (ii) into (40):

(i) $\lambda \mathrm{P} \lambda \mathrm{x} \lambda \mathrm{e}[\{\mathrm{s} \bigcirc \mathrm{e} \& \mathrm{~s}: \neg[\mathrm{P} \mathrm{x}]\}[\mathrm{e}:[\operatorname{BECOME}[\mathrm{P} \mathrm{x}]]]]$

(ii) $\lambda \mathrm{x} \lambda \mathrm{e}[\{\mathrm{s} \bigcirc \mathrm{e} \& \mathrm{~s}: \neg[\lambda \mathrm{z}[$ famous $\mathrm{z}] \mathrm{x}]\}[\mathrm{e}:[\operatorname{BEcome}[\lambda \mathrm{z}[$ FAmous $\mathrm{z}] \mathrm{x}]]]]$

22 The correspondence between become and remain is less clear-cut than e.g. the relation between werden 
(41) a. The kids remained ill.

b. The kids didn't become healthy.

c. The kids were ill.

Notice first, that if (41)(a) is true, the simple copula clause (41)(c) must also be true, while the reverse does not hold: The truth of (41)(c) does not imply (41)(a), which asserts the continuation of the state in question. In this respect, the state expressed by the copula clause behaves like the target state of an inchoative construction. The next point to be noted is that (41)(a) does not simply assert the continuation of sickness, as would e.g. The kids were still sick, it more specifically denies the change leading from the source to a different target state. This is what makes it equivalent to $(41)(b)$, where the denial of the change to the complement state is expressed explicitly. ${ }^{23}$ Finally, both (41)(a) and (b) share the same presupposition expressed by the copula clause (41)(c), provided the relevant temporal ordering is assumed. More generally, remain presupposes the predicated state $\mathrm{p}$, and it denies the transition to $\neg \mathrm{p}$. This comes out automatically, if we set up the lexical entry (42), whose SF differs from that of become just by the negation of the transition:

$$
\text { / remain / } \quad[+\mathrm{V},-\mathrm{N}] \quad \lambda \mathrm{P} \lambda \mathrm{x} \lambda \mathrm{e}[\mathrm{e}: \neg[\operatorname{BECOME} \neg[\mathrm{P} \mathrm{x}]]]
$$

A couple of remarks are to be added here. First, (42) is incomplete in several respects. It doesn't take care e.g. of cases like nothing of the book remained, where $\mathrm{P}$ is syntactically empty, but must semantically be interpreted as a kind of existential predication. This in turn has to do with the status of the argument position $\lambda \mathrm{P}$ and the morpho-syntactic constraints to be associated with it. They are similar, but obviously not identical to those associated with the corresponding position of become. I will leave aside these issues for the time being, turning to a second remark: We clearly must expect the constraint (34) to apply in order to get (43), specifying the required presupposition, viz. the negation of the target state:

$$
\text { /remain/ } \quad[+\mathrm{V},-\mathrm{N}] \quad \lambda \mathrm{P} \lambda \mathrm{x} \lambda \mathrm{e}[\{\mathrm{s} \bigcirc \mathrm{e} \& \mathrm{~s}:[\mathrm{P} x]\}[\mathrm{e}: \neg[\operatorname{BECOME} \neg[\mathrm{P} \text { x }]]]]
$$

In order to derive (43) from (42) by means of (34), we must however, deal with the fact that BECOME is in the scope of negation in (42), but not in (34) - or in the entry (38) for become, for that matter. Intuitively, one would like to claim that (34), as it takes care of the presupposition to be triggered, by the very nature of presuppositions holds for both the positive and the negative condition the presupposition is associated with. Hence (34) would apply to [BECOME p], irrespective of the negation that prefixed in (42). Although this claim seems to me right in spirit, it is insufficient for two reasons. First, the consideration just mentioned applies to the external

and bleiben in German, which lacks competitors like get and keep. The main points, however, seem to be as clear as they are in German and can reasonably be discussed with respect to remain as the paradigm case.

23 It might be noted that literally speaking the negation of the change implies the negation of the target state only as a consequence of the presupposed source state whose change is denied. Hence if the presupposition is rejected - as in The kids didn't become healthy, they simply were not sick at all - the result of a negated change would not be the negated target state. 
negation, but not to the negation within the scope of BECOME, which clearly must be respected, because otherwise we would derive the wrong presupposition. Hence the fact that the external (but not the internal) negation is to be ignored must somehow be indicated in (34). Second, this requirement seems to be part of a more general issue to be taken up with respect to causative verbs. Finally, it is the occurrence of the negation "inside" and "outside" of BECOME in (42), that makes remain the dual counterpart of become. ${ }^{24}$

As a consequence of this, the presupposed state, being the negation of a negative state, comes out as a positive condition.

For the sake of illustration, (44) represents the verb phrase remain ill, assuming that the SF of ill may be abbreviated as [ $\neg[$ HEALTHY x ] ], which leaves the target state [ HEALTHY $\mathrm{x}]$ by canceling the double negation out.

$$
\begin{aligned}
& \text { / remain ill / }[+\mathrm{V},-\mathrm{N}] \\
& \lambda \mathrm{x} \lambda \mathrm{e}[\{\mathrm{s} \bigcirc \mathrm{e} \& \mathrm{~s}:[\neg[\text { HeALthy } \mathrm{x}]]\}[\mathrm{e}: \neg[\text { BECOME }[\text { HeALthy } \mathrm{x}]]]]
\end{aligned}
$$

It is easy to figure out that on the basis of these assumptions the SF of not become healthy must come out practically identical to that in (44). In much the same way, the equivalence between predications with remain and negated inchoatives as illustrated in (45) and (46) can be accounted for:

(45) a. The shop remains closed.

b. He remained in Paris for weeks.

c. The dog remained alive.

(46) a. The shop doesn't open.

b. He didn't leave Paris for weeks.

c. The dog didn't die.

Examples like these bring up an intriguing problem, once we switch the negation:

24 We might deal with this duality as a relation between constants of SF rather than lexical entries, by setting up a postulate like (i), which then would naturally lead us to replace (42) by the entry (ii):

(i) REMAIN $\mathrm{p} \leftrightarrow \neg[$ BECOME $\neg[\mathrm{p}]]$

(ii) /remain/ [+V, -N] $\lambda \mathrm{P} \lambda \mathrm{x} \lambda \mathrm{e}[\mathrm{e}:[\operatorname{REMAIN}[\mathrm{P} \mathrm{x}]]]$

I will not adopt here this alternative analysis for two reasons. First, we need the postulate (i) only to introduce an additional primitive element of SF, all the properties of which are captured by the combination $\neg$ BECOME $\neg$. Furthermore, we would not only have to set up (iii) - in addition to (34) - to account for the presupposition induced by REMAIN, we would also need (iv) to account for its implication, as discussed before, as (34) and (31) would not apply to REMAIN:

(iii) $[\mathrm{e}:[\operatorname{REMAIN}[\mathrm{p}]] \Rightarrow[\{\mathrm{s} \bigcirc \mathrm{e} \& \mathrm{~s}:[\mathrm{p}]\}[\mathrm{e}:[\operatorname{REMAIN}[\mathrm{p}]]]]]$

(iv) (e: [REMAIN $\mathrm{p}]$ is true at $\mathrm{t}$ ) implies ( $\mathrm{s}^{\prime}:[\mathrm{p}]$ is true at some $\mathrm{t}^{\prime}$ with $\mathrm{t}^{\prime} \bigcirc \mathrm{t}, \mathrm{t}^{\prime} \bigcirc \mathrm{t}^{\prime \prime}, \mathrm{t}^{\prime}<\mathrm{t}^{\prime \prime \prime}$ ). 
(47) a. The shop doesn't remain closed tonight.

b. The shop opens tonight.

c. The shop is open tonight.

(48) a. The kids didn't remain ill.

b. The kids became healthy.

c. The kids weren't ill.

Most of the comments apply as before. Consider e.g. (48), which corresponds to (41), except that positive and negative predications are exchanged, preserving the presupposition - the kids being ill -, but target states exchanged, as expected. The problem to be noted concerns the stateand event-properties: While negated events like (41)(b) behave in crucial respects like a state, as shown in (49), a negated non-event, if that is what remain expresses, does not become an event, as (50) indicates. $^{25}$

(49) a. The kids didn't become healthy for two months.

b. The shop doesn't open for two hours.

(50) a. \#The kids didn't remain ill in two months.

b. \#The shop doesn't remain closed in two hours.

Clearly, (50) cannot mean that the kids became healthy in two months, or that the shop opens in two hours. What this means is that the clausal negation and the negation within the SF of remain do not cancel out each other in cases like (50). A preliminary consequence to be drawn from this observation is to distinguish between (a) $[\neg[\mathrm{e}: \mathrm{p}]]$ and (b) $[\mathrm{e}: \neg[\mathrm{p}]]$, where (a) could result from clausal negation, while (b) is a lexical property. Although there are further problems to be taken into consideration, I will assume for the time being that the entry for remain is at least on the right track in this respect.

A final comment is to be made with respect to causative verbs like those in (51), which share the presupposed state of their inchoative counterparts in (52), indicated in (53):

25 Things are fairly complicated here, because judgments may rely on the possibility mentioned above, to let durational adverbials qualify the target state, as in he came in for a few minutes, such that the acceptability sentences like (49) can be construed as qualifying either the negated event or the negated result, which factually amounts to the same. Somewhat different interpretive options blur the judgment with respect to temporal limitations, as in (i) and (ii), which might be construed in analogy to construction like with this medicine, he slept in a few minutes, where slept is interpreted as fell asleep:

(i) ${ }^{(?)}$ The kids didn't become healthy in two month.

(ii) ${ }^{(?)}$ The shop doesn't open in two hours.

As the temporal structure of events is not our main concern, I will not pursue the issue any further. 
(51) a. Fred opened the shop the next day.

b. The sun dried the sheets quickly.

c. The book made the author famous.

d. The police killed the ferocious dog.

(52) a. The shop opened the next day.

b. The sheets dried quickly.

c. The author became famous.

d. The ferocious dog died.

(53) a. The shop was not open.

b. The sheets were wet.

c. The author was not famous.

d. The ferocious dog was alive.

Before turning to the computation of presuppositions for causative verbs, two side-issues might be mentioned, which need not concern us here. First, causative verbs (and causative constructions in general) mostly, but not necessarily involve inchoativity, which is the source of the presupposition we are looking at. But causation may be responsible for states, rather than events. (54) illustrates causation without inchoativity:

(54) a. The new engine turns the wheel very steadily.

b. The fire brigade held the rope tight.

Here, no change of state is asserted or negated, hence no presupposed state is to be computed. Second, causatives may introduce further presuppositions, due to the required type of agent or the sort of causation. (55) illustrates some possibilities:

(55) a. They strangled the night-watchman.

b. Two hooligans stabbed the foreigner.

Whatever presuppositions strangle, stab and other verbs might add to the conditions of killing they need not concern us here, except that we must make sure that they do not interfere with the construction of the presupposition induced by BECOME, to which I will turn now.

The basic schema of causative verbs has already been sketched with respect to the ambiguity of open in (23)(b) above, which I repeat here for the sake of discussion:
b. / open /
$[+\mathrm{V},-\mathrm{N}]$
$\lambda \mathrm{x} \lambda \mathrm{y} \lambda \mathrm{e}[\mathrm{e}$
: [[ACT y] [CAUSE [BECOME [OPEN x]]]]] 
What we need to provide is the presupposition triggered by the inchoative open incorporated in (23)(b). This should, of course, in principle be accomplished by the constraint (34). To this effect, two problems must be clarified, however.

The first of these problems was already mentioned with respect to negation showing up in remain. The generalization hinted at in that connection must deal with the fact that the presupposition of BECOME is to be computed locally, i.e. without regard of the operators taking BECOME as argument. The elements to be ignored would then include not only the negation, as discussed earlier, but also the causative operator - or more correctly CAUSE and the specification of the causing event. To this effect, (34) would have to be modified as shown in (34'), indicating that BECOME triggers its presupposition, also if it is subordinate to other operators:

$$
[\mathrm{e}:[\ldots[\operatorname{BECOME}[\mathrm{p}]]]] \Rightarrow[\{\mathrm{s} \bigcirc \mathrm{e} \& \mathrm{~s}: \neg[\mathrm{p}]\}[\mathrm{e}:[\ldots[\text { BECOME }[\mathrm{p}]]]]]
$$

The locality intended by this formulation is subject to crucial conditions governing the computation of the presuppositional component $\mathrm{P}$ for arbitrary complex expressions ${ }^{26}$. These conditions must, among others, guarantee the clause headed by a given verb as the domain gathering the pertinent presuppositions. Thus the embedded clause (John) to have opened the window in (56)(a) and (b) must have the presupposition the window was closed, although this becomes a presupposition of the matrix clause only within the scope of the factive verb regret, but not of the non-factive verb believe:
a. $\mathrm{John}_{i}$ believed $\left[e_{i}\right.$ to have opened the window]
b. $\mathrm{John}_{i}$ regretted $\left[e_{i}\right.$ to have opened the window]

This would fall out naturally, if we assume that presuppositions are unified with respect to the event variable, which defines in a way the boundary of the domain in (34').

This gets us to the second, more intricate problem. Notice that the relation between causative and inchoative verbs explicitly exploited in notational variant (24) shifts the event reference represented by "e" from the change of state to the causation of the change. This is intuitively correct, as far as the verb's event reference is concerned, but it requires clarification of the temporal relation between the causation and the caused change, since the presupposition must be temporally located in this respect. As discussed above, the time structure of a change of state is not a trivial issue, the change being defined only by the intervals it overlaps. An even more intricate problem is the temporal location of the event represented as e: [p CAUSE $q$ ] with respect to the time of $p$ and q. Consider, for example, a simple case like Fred opened the door. In the simplest case, Fred's activity and the position of the door have the same location in time. But suppose Fred opens the door pushing a button that releases the door, for reasons of security, with a delay of three min-

26 There is a large literature on the so-called projection problem of presuppositions dealing with these conditions. A first systematic integration of the conditions in question has been proposed in Karttunen and Peters (1979). The problem is taken up in Kamp (2001) from a somewhat different perspective, which I will adopt here as background. 
utes. Then the time of $\mathrm{p}$ precedes that of $\mathrm{q}$, without even a temporal overlap between $\mathrm{p}$ and $\mathrm{q} .{ }^{27}$ There are two strategies to deal with these problems in view of (34'). The first option is to rely on the fact that configurations of the type [p [CAUSE [BECOME q]]] are always to be construed as direct causation, not allowing for any explicitly indicated intermediate events. With this proviso, the source state of the change [BECOME $q$ ] will just as well be a presupposition for the change in question as for its causation. With this construal, (34') would account for the presupposition of both the inchoative and the causative verbs. The second option takes into account the different events e and $\mathrm{e}^{\prime}$, instantiating [p [CAUSE q]], and q, respectively, with a corresponding reformulation of (43'). As this reformulation would be reasonable only if it takes into account further considerations, which go beyond the scope of the present concern, I will adopt the first option, assuming that (34') so far correctly computes the presupposition associated with BECOME.

These considerations carry over to the relatively small group of verbs where causativity combines with the negation of inchoativity. A case in point is keep in one of its readings, as exemplified in (57):

(57) a. Max kept the kids running.

b. Mary didn't keep these things in good shape.

The presupposition in (a) is that the kids were running, so that Max caused them to continue, while (b) presupposes, that things were in good shape and denies that Mary caused the continuation of this state. (58) is an entry from which these conditions would follow: ${ }^{28}$

$$
\begin{gathered}
\text { /keep/ } \quad[+\mathrm{V},-\mathrm{N}] \lambda \mathrm{P} \lambda \mathrm{x} \lambda \mathrm{y} \lambda \mathrm{e}[\mathrm{e}:[[\text { ACT } \mathrm{y}][\text { CAUSE } \neg[\text { BECOME } \neg[\mathrm{P} \text { x }]]]]] \\
{[\mathrm{X}]}
\end{gathered}
$$

The morpho-syntactic condition indicated by $[\mathrm{X}]$ has to specify the properties characterizing the different predicatives keep allows for. Thus in keep them running "P" is replaced by the SF of them running, which eventually gives (59):

$$
\begin{aligned}
& \text { /keep them running/ }[+\mathrm{V},-\mathrm{N}] \\
& \lambda \mathrm{y} \lambda \mathrm{e}[\underline{x} \mid\{\mathrm{s} \bigcirc \mathrm{e} \wedge \mathrm{s}:[\operatorname{RUNx}]\}[\mathrm{e}:[[\text { ACT } \mathrm{y}][\mathrm{CAUSE} \neg[\operatorname{BECOME} \neg[\mathrm{P} \mathrm{x}]]]]]]
\end{aligned}
$$

27 The problem has been discussed, among others, in Dowty (1979), where three possibilities are considered: the time of e: [ $p$ CAUSE q] coincides with (a) the time of q, (b) the time of p, and (c) the smallest interval that overlaps with the time of $\mathrm{p}$ and the time of $\mathrm{q}$. Dowty considers (c) as the most plausible solution in most cases.

28 The various other readings of keep are, of course, not unrelated to the one considered here. They are thus subject to similar considerations like the entries for open, get, etc. discussed earlier. Thus the relation between (57)(a) and the intransitive counterpart The kids kept running could be captured by a complex entry like (i), using the notational devices mentioned above:

(i) $/ \mathrm{keep} / \quad[+\mathrm{V},-\mathrm{N}] \quad \lambda \mathrm{P} \lambda \mathrm{x}\left({ }_{\alpha} \lambda \mathbf{y}\right) \lambda \mathrm{e}\left[\mathrm{e}:\left[\left({ }_{\alpha}[\right.\right.\right.$ ACT $\mathrm{y}][\mathrm{CAUSE}) \neg[$ BECOME $\left.\left.\left.\neg[\mathrm{P} \mathrm{x}]]\right]\right]\right]$ $[\mathrm{Y}]$

I will not go into those issues, being concerned here primarily with the computation of presuppositions. 
The underlined variable " $\underline{x}$ " is a provisional indication of the discourse referent introduced by the pronoun they (or them, for that matter), which binds the argument $\mathrm{x}$ of RUN: ${ }^{29}$

\section{Become, Events, and Processes}

In this section, I will take up the subtle, but intricate difference illustrated in (60) and (61), in order to show how it can be accommodated by the analysis of BECOME proposed so far.

(60) a. The heap became six feet high \{within two days/\# for quite a while\}.

b. The heap became higher than six feet $\{$ within two days/\# for quite a while\}.

c. The heap became higher (and higher) $\left\{{ }^{\#}\right.$ within two days/for quite a while $\}$.

(61) a. Hans wurde in kurzer Zeit/\# eine Weile lang $\}$ so groß wie Paul. ( $\{$ In a short time/\# for quite a while $\}$, Hans became taller than Paul.)

b. Hans wurde $\{$ in kurzer Zeit/\# eine Weile lang $\}$ größer als Paul. ( $\{$ In a short time/\# for quite a while $\}$, Hans became taller than Paul.)

c. Hans wurde $\left\{{ }^{\#}\right.$ in kurzer Zeit/eine Weile lang $\}$ (immer) größer. ( $\{$ \# In a short time/for quite a while $\}$ Hans became taller (and taller).)

What is at issue is the fact that the (a)- and (b)-sentences express changes with a well defined target state in the sense discussed so far, whereas the (c)-sentences describe processes not terminating in a final result state, as borne out by the mutually exclusive temporal adverbials they naturally combine with. Correspondingly, the (a)- and (b)-sentences make the usual presupposition - the heap was not six feet high and not higher than six feet in (60)(a) and (b), respectively, Hans was not as tall as and not taller than his brother in (61)(a) and (b), respectively - while it seems to be fairly unclear what happens to the presupposition in the (c) sentences. I will try to clarify these problems in three steps.

First, as the issue clearly has to do with the semantics of comparatives, I will begin with a sketch of the relevant ingredients of positive and comparative adjectives. Relying on proposals discussed in Bierwisch (1989), the elements minimally needed for an adjective like high and its antonym low are indicated in (62), where VERT abbreviates a function that assigns an object $\mathrm{x}$ its vertical extension (or position), i.e. its height, which is then related to the sum $[\mathrm{v}+\mathrm{d}]$ or the difference $[\mathrm{v}$ $-\mathrm{d}$ ], indicating that the height exceeds or falls short of some value $\mathrm{v}$ by some difference $\mathrm{d}^{30}$ :

29 The notational proposal to represent discourse referents as a component of SF, separated by |, is adopted from Maienborn (2002).

30 The value of [VERT $\mathrm{x}$ ] is not simply equal to $[\mathrm{v}+\mathrm{d}]$, but must cover or even exceed it. This must be assumed for a number of reasons, one being the fact that negating [[VERT $x] \geq[\mathrm{v}+\mathrm{d}]]$ does not allow [VERT $\mathrm{x}]$ to be greater than $[\mathrm{v}+\mathrm{d}]$. Hence $[[\operatorname{VERT} \mathrm{x}] \geq[\mathrm{v}+\mathrm{d}]]$ means [VERT $\mathrm{x}]$ is not less than $[\mathrm{v}+\mathrm{d}]$, with $[[\operatorname{VERT} \mathrm{x}]=[\mathrm{v}+\mathrm{d}]]$ as default interpretation. The same consideration holds for the converse relation $\leq$ in the antonym low, where the value of [VERT $\mathrm{x}]$ is less than or equal to $[\mathrm{v}-\mathrm{d}]$. 

a. /high/ $[+\mathrm{N},+\mathrm{V}]$
( $\lambda \mathrm{d}) \lambda \mathrm{x}[[\operatorname{VERT} \mathrm{x}] \geq[\mathrm{v}+\mathrm{d}]]$
b. /low/ $[+\mathrm{N},+\mathrm{V}]$
( $\lambda \mathrm{d}) \lambda \mathrm{x}[[\operatorname{VERT} \mathrm{x}] \leq[\mathrm{v}-\mathrm{d}]]$

The amount of $\mathrm{d}$ might be specified by a measure phrase, as in (60)(a), or it might be left implicit, as in the heap was high. This is indicated by the optionality of the position " $\lambda \mathrm{d}$ ". If $\mathrm{d}$ is left implicit, the value of $\mathrm{v}$ must be something like the expected standard or normal case $\mathrm{N}$, while the specification of d, e.g. by the value of six feet, requires d to be measured from the ground, such that the value of $\mathrm{v}$ must be $0 .{ }^{31}$ In other words, $\mathrm{v}$ is a kind of parameter, the two values of which are $\mathrm{N}$ and 0 , chosen according to general principles of interpretation. With these assumptions, we get the VP-representations in (64), if (63) abbreviates the entry for the copula be, discussed a.o. in Bierwisch (1997), Maienborn (2002):

$$
\text { /be/ } \quad[+\mathrm{V},-\mathrm{N}] \quad \lambda \mathrm{P} \lambda \mathrm{x} \lambda \mathrm{s}[\mathrm{s}:[\mathrm{P} \mathrm{x}]]
$$
a. /be six feet high/ $\quad[+\mathrm{V},-\mathrm{N}] \quad \lambda \mathrm{x} \lambda \mathrm{s}[\mathrm{s}:[[\operatorname{VERT} \mathrm{x}] \geq[0+6$ FEET $]]$
b. /become six feet high/ $\quad[+\mathrm{V},-\mathrm{N}]$
$\lambda \mathrm{x} \lambda \mathrm{e}[\{\mathrm{s} \bigcirc \mathrm{e} \& \mathrm{~s}: \neg[[\operatorname{VERT} \mathrm{x}] \geq[0+6$ FEET $]]\}$
$[\mathrm{e}:[$ BECOME $[[\operatorname{VERT} \mathrm{x}] \geq[0+6$ FEET $]]]]]$

It might be worth noticing that in (64)(b) the presupposition induced by BECOME is correctly specified as just the negation of the target state: Eventually the heap became six feet high presupposes that the heap was six feet high was false before the change, without any specification of the heap's height (or even existence) - except that it could not be six feet or more.

The second step is to supply the comparative, whose essence is to provide an explicit possibility to specify the value of $\mathrm{v}$ as a standard of comparison, which is the six feet in (60)(b), and (the height of) Paul in (61)(b). Putting aside the non-trivial matters involved in morphological rules deriving higher than from high, the essential point can be expressed by the following entries for comparative adjectives, which provide an additional argument position, making the variable $\mathrm{v}$ available for syntactically specified values:
a. /high+er/ $[+\mathrm{N},+\mathrm{V}]$
( $\lambda \mathrm{d}) \lambda \mathrm{v} \lambda \mathrm{x}[[\operatorname{VERT} \mathrm{x}] \geq[\mathrm{v}+\mathrm{d}]]$
b. /low + er/ $\quad[+\mathrm{N},+\mathrm{V}]$
( $\lambda \mathrm{d}) \lambda \mathrm{v} \lambda \mathrm{x}[[\operatorname{VERT} \mathrm{x}] \leq[\mathrm{v}-\mathrm{d}]]$

On the basis of these entries, VPs like (66) can be constructed, where the optional position " $\lambda \mathrm{d}$ " is omitted, hence d is unspecified, while v is replaced by the SF of six feet:

31 This explains, by the way, why *two feet low is anomalous: Since the negative adjective requires the value of $d$ to be subtracted from $v$, no height would result if $v$ is 0 . This does not hold, as we will see immediately, for the well-formed two feet lower, since the comparative provides a value for $\mathrm{v}$ that is necessarily different from 0 . - It might be noted at this point that there is general agreement with respect to the ingredients of this analysis, although they have been formulated in a number of different ways. For surveys see von Stechow (1984) and Bierwisch (1989). 
(66)
a. /be higher than six feet/
$[+\mathrm{V},-\mathrm{N}]$
$\lambda \mathrm{x} \lambda \mathrm{s}[\mathrm{s}:[[\operatorname{VERT} \mathrm{x}] \geq[6$ FEET $+\mathrm{d}]]]$
b. /be lower than six feet/
$[+\mathrm{V},-\mathrm{N}]$
$\lambda \mathrm{x} \lambda \mathrm{s}[\mathrm{s}:[[$ VERT $\mathrm{x}] \leq[6$ FEET $-\mathrm{d}]]]$

Notice that in (66)(a) - differing from (64)(a) - 6 FEET is the value of v, rather than the difference variable $\mathrm{d}$, which may be additionally specified, as shown in ten inches higher than six feet or twelve inches lower than ten feet. With these independently motivated ingredients the representation of the VP of (60)(b) seems to be straightforward:

$$
\begin{aligned}
& \text { /become higher than six feet/ }[+\mathrm{V},-\mathrm{N}] \\
& \lambda \mathrm{x} \lambda \mathrm{e}[\underline{\mathrm{v}} \mid\{\mathrm{s} \bigcirc \mathrm{e} \& \mathrm{~s}: \neg[[\operatorname{VerT} \mathrm{x}] \geq[\mathrm{v}+\mathrm{d}]]\}[\mathrm{e}:[\text { BeCOME }[[\operatorname{VERT} \mathrm{x}] \geq[\mathrm{v}+\mathrm{d}]]]]]
\end{aligned}
$$

A remark is necessary here concerning the implicit variable " $d$ ", which I have construed in (67) as a kind of parameter, the value of which is automatically copied by the constraint (34'). This seems to be correct in view of the fact that " $d$ " can be explicitly specified in constructions like become ten inches higher that six feet, where " $\mathrm{d}$ " has the value of ten inches. With this proviso, (67) correctly specifies the shift to x's exceeding the height of six feet by d, presupposing that it did not before the change. Even though this seems to be the appropriate treatment of $\mathrm{d}$ in cases like (60)(b), we have to consider further aspects, as we proceed.

The third step has to provide an account of the process expressed by the (c)-sentences in (60) and (61). One point to notice here is that constructions like these are ambiguous between the process reading in question and an event-reading, which is possible only if the optional repetition higher and higher in (60) and the optional adverbial immer (always) in (61) are omitted. This event reading differs from the (b)-sentences by its lack of an explicitly specified value for $\mathrm{v}$, relying on some contextually given value to compare with. Under this interpretation, (60)(c) is in a way elliptical, leaving the argument position " $\lambda \mathrm{v}$ " unsaturated. The VP that accounts for this reading

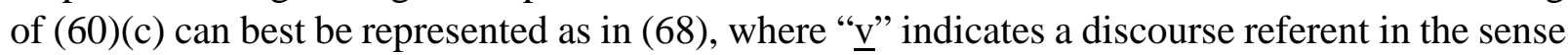
mentioned earlier. Thus " $\underline{v}$ " indicates a contextually specified discourse referent, which supplies the lacking than-complement (say the height of the wall nearby), and it correspondingly binds also the occurrence of " $\mathrm{v}$ " in the presupposition:

$$
\begin{aligned}
& \text { /become higher/ } \quad[+\mathrm{V},-\mathrm{N}] \\
& \lambda \mathrm{x} \lambda \mathrm{e}[\underline{\mathrm{v}} \mid\{\mathrm{s} \bigcirc \mathrm{e} \& \mathrm{~s}: \neg[[\operatorname{veRT} \mathrm{x}] \geq[\mathrm{v}+\mathrm{d}]]\}[\mathrm{e}:[\operatorname{BECOME}[[\operatorname{VerT} \mathrm{x}] \geq[\mathrm{v}+\mathrm{d}]]]]]
\end{aligned}
$$

It should furthermore be noted in passing that this reading is compatible with a measure phrase specifying the value of " $\mathrm{d}$ ", as in the heap became ten inches higher (than the wall), which suggests, that not only v, but also "d" be copied in the negated condition of the presupposition.

The crucial point now is the treatment of the process reading. This reading characteristically excludes any explicit specification of the values for either "v" or " $d$ ", as (69) shows:

(69) a. The heap became (*two feet) higher and higher (*than the wall).

b. Hans wurde $(* 10 \mathrm{~cm})$ immer größer (*als Paul). (Hans became $(* 10 \mathrm{~cm})$ taller and taller (*than Paul).) 
The actual impact of (69) is that the process reading does not only prevent explicitly specified values for either "v" or "d", it induces in fact a completely different regime over these variables. The intuitive notion that suggests itself is that the process is to be construed as a continuous sequence of changes each of which adds some amount $d$ to the value $v$ reached before. This means with respect to " $v$ ", that it must not refer to any discourse referent of its own, but merely to a value defined by the previous state of $\mathrm{x}$. With respect to " $\mathrm{d}$ ", its value can only be determined by the successive states of $x$ and the value of [VERT $x$ ] along these states. In other words, the process reading of become + Comparative takes an earlier state of $\mathrm{x}$ as defining the value of " $\mathrm{v}$ ". This allows neither " $v$ " nor " $d$ " to be specified by values external to the process of $x$ 's continuous changing. In order to make this notion more explicit, let $\mathrm{v}_{i}$ be the value of [VERT $\mathrm{x}$ ] at some time $\mathrm{t}_{i}$, where $\mathrm{t}_{i}$ precedes the time $\mathrm{t}_{i}^{\prime}$ of the target state $\mathrm{s}^{\prime}$ of the event e under description. Suppose furthermore that we represent by " $\mathrm{d}_{i}$ " the difference between the value of [VERT $\mathrm{x}$ ] at $\mathrm{t}_{i}$ and $\mathrm{t}_{i}^{\prime}$, such that the value of $[$ VERT $\mathrm{x}]$ reaches $\left[\mathrm{v}_{i}+\mathrm{d}_{i}\right]$ at $\mathrm{t}_{i}^{\prime}$. With this assumption we get (70)(a) as a possible representation for the incremental steps constituting the process in question, with (34') computing the standard presupposition spelled out in (70)(b):
$\begin{array}{lll}\text { a. } & \text { /become higher/ } \quad[+\mathrm{V},-\mathrm{N}] \\ \text { b. } & \text { /become higher/ } \quad[+\mathrm{V},-\mathrm{N}]\end{array}$
$\lambda \mathrm{x} \lambda \mathrm{e}\left[\mathrm{e}:\left[\right.\right.$ BeCOME $\left.\left.\left[[\operatorname{VerT} \mathrm{x}] \geq\left[\mathrm{v}_{i}+\mathrm{d}_{i}\right]\right]\right]\right]$
$\lambda \mathrm{x} \lambda \mathrm{e}\left[\left\{\mathrm{s} \bigcirc \mathrm{e} \& \mathrm{~s}: \neg\left[[\operatorname{Vert} \mathrm{x}] \geq\left[\mathrm{v}_{i}+\mathrm{d}_{i}\right]\right]\right\}\left[\mathrm{e}:\left[\operatorname{BeCOME}\left[[\operatorname{vert} \mathrm{x}] \geq\left[\mathrm{v}_{i}+\mathrm{d}_{i}\right]\right]\right]\right]\right]$

The presupposition in (70)(b) requires [VERT $\mathrm{x}]$ to be below $\left[\mathrm{v}_{i}+\mathrm{d}_{i}\right]$ before the change instantiated by e takes place. This condition, although apparently correct, leaves a problem to be clarified, because it is crucially less specific than the assumption already made, namely that $[[$ VERT $\mathrm{x}]=$ $\left.\mathrm{v}_{i}\right]$ holds at $\mathrm{t}_{i}$. Now the condition $\neg\left[[\right.$ VERT $\left.\mathrm{x}] \geq\left[\mathrm{v}_{i}+\mathrm{d}_{i}\right]\right]$ (or its formal equivalent $\left[[\right.$ VERT $\mathrm{x}]<\left[\mathrm{v}_{i}\right.$ $\left.\left.+\mathrm{d}_{i}\right]\right]$ ) converges with this condition to exactly the degree to which $\mathrm{d}_{i}$ approximates 0 . In other words, $\mathrm{t}_{i}$ with the condition $\left[[\right.$ VERT $\left.\mathrm{x}]=\mathrm{v}_{i}\right]$ becomes a more specific condition imposed on the presupposed source state of e, if we take $d=0$ in the presupposition. With this consideration in mind, we may replace (70)(b) by the more restrictive (70)(c):

$$
\begin{aligned}
& \text { c. /become higher/ }[+\mathrm{V},-\mathrm{N}] \\
& \lambda \mathrm{x} \lambda \mathrm{e}\left[\left\{\mathrm{s} \bigcirc \mathrm{e} \& \mathrm{~s}:\left[[\operatorname{verT} \mathrm{x}]=\mathrm{v}_{i}\right]\right\}\left[\mathrm{e}:\left[\text { BeCOMe }\left[[\operatorname{vert~x}] \geq\left[\mathrm{v}_{i}+\mathrm{d}_{i}\right]\right]\right]\right]\right]
\end{aligned}
$$

Notice that no specific condition on the time $\mathrm{t}_{i}$ fixing $\mathrm{v}_{i}$ is needed: It simply precedes the final state of e, according to the conditions holding at both states. What should be observed, however, is the specific regime that this option requires for the variables " $v_{i}$ " and " $\mathrm{d}_{i}$ ". We already noted that they are not available for syntactically specified values, and they are not open to contextual interpretation either although they are under strict, albeit implicit, control. The variable $\mathrm{v}$ in expressions like (62), for which the comparative would create a special argument position, now obviates any recourse to either syntactic or contextual specification. The same holds for $d$ in (62), whose counterpart in (70) is moreover subject to its own specific conditions, indicated by the value $\mathrm{d}_{i}$. As $\mathrm{d}_{i}$ was introduced to represent the difference between the extent of [VERT x] at $\mathrm{t}_{i}$ and $\mathrm{t}_{i}^{\prime}$, its actual value is dependent on $\mathrm{v}_{i}$ and $\mathrm{t}$. As a matter of fact, the value of $\mathrm{d}$ under this construal becomes a function of $\mathrm{v}_{i}$ and $\mathrm{t}$; it ceases to be an independent parameter, in case it is not explicitly specified. In order to see to what extent these assumptions - and representations like (70) that rely on them - provide an appropriate account of the process character of getting higher (and higher), two problems need to be clarified. 
First, as already mentioned, become higher in the relevant reading of (60)(c) is supposed to express a continuous change, while (70) seems to represent a single event instead of a homogeneous process. Second, as (60)(c) is neither elliptical nor open for explicit specification, the origin of $\mathrm{v}_{i}$ that provides the value of comparison needs to be clarified. These problems, which are not independent of each other, shall be discussed in turn.

The basic intuition about states and processes has been made explicit e.g. in Bach (1986): Each part of a process e must meet the same condition as e as a whole. Complying with this requirement, each part of x's getting higher is itself an instance of x getting higher. This intuition can be captured in two ways. The first is to explicitly turn the eventuality e referred to in cases like (70) into a (potentially infinite) set of sub-eventualities all subject to the condition expressed in (70), a proposal sketched a.o. in Bierwisch (2000). The necessary 'grinding' of e can be accomplished by a template like (71), which distributes the condition $\mathrm{P}$ from an $\operatorname{argument} \mathrm{z}$ to its (im)proper parts, thus warranting the decisive property of processes (as well as mass terms):

$$
\lambda \mathrm{P} \lambda \mathrm{z}\left[\forall \mathrm{z}_{k}\left[\mathrm{z}_{k} \subseteq \mathrm{z}\right]\left[\mathrm{P}_{k}\right]\right]
$$

A well known case in point is the mass interpretation of count nouns like chicken in examples like There was chicken all over the plate. ${ }^{32}$ Applying this template to (70)(a), we derive $(72)^{33}$ :

$$
\text { /become higher/ } \quad[+\mathrm{V},-\mathrm{N}] \quad \lambda \mathrm{x} \lambda \mathrm{e}\left[\forall \mathrm{z}_{k}\left[\mathrm{z}_{k} \subseteq \mathrm{e}\right]\left[\mathrm{z}_{k}:\left[\operatorname{BECOME}\left[[\operatorname{VERT} \mathrm{x}] \geq\left[\mathrm{v}_{i}+\mathrm{d}_{i}\right]\right]\right]\right]\right]
$$

This leaves us with the task to relate the variable " $\mathrm{v}_{i}$ " indicating the height at the previous stage to the sub-event $\mathrm{z}_{k}$. Intuitively, one would like to say that $\mathrm{v}_{i}$ is the value of [VERT $\mathrm{x}$ ] resulting from the previous sub-event $\mathrm{z}_{k-1}$. A moment's reflection shows that this is already inherent in the stipulation by which $\mathrm{v}_{i}$ was introduced, according to which $\mathrm{t}_{i}$ has to precede $\mathrm{t}_{i}^{\prime}$, and $\mathrm{t}_{i}$ is moreover the time of the source state of e, according to the reasoning underlying (70)(c). Hence without further stipulation, we get (73) with the presupposition spelled out as discussed with respect to (70)(c) where $\mathrm{i}<\mathrm{k}$ and $\mathrm{t}_{i}<\mathrm{t}_{k}$ for arbitrary $\mathrm{i}$ and $\mathrm{k}$.

$$
\begin{aligned}
& \text { /become higher/ } \quad[+\mathrm{V},-\mathrm{N}] \\
& \left.\lambda \mathrm{x} \lambda \mathrm{e}\left[\forall \mathrm{z}_{k}\left[\mathrm{z}_{k} \subseteq \mathrm{e}\right]\left\{\mathrm{s}_{k} \bigcirc \mathrm{z}_{k} \& \mathrm{~s}_{k}:\left[[\operatorname{VERT} \mathrm{x}]=\mathrm{v}_{i}\right]\right]\right\}\left[\mathrm{z}_{k}:\left[\operatorname{BECOME}\left[[\operatorname{VERT} \mathrm{x}] \geq\left[\mathrm{v}_{i}+\mathrm{d}_{i}\right]\right]\right]\right]\right]
\end{aligned}
$$

What (73) in fact expresses is that e consists of sub-events $z_{k}$, each of which presupposes a state where the height of $\mathrm{x}$ is $\mathrm{v}_{i}$ and end in a state where it is $\mathrm{v}_{i}+\mathrm{d}_{i}$, which then becomes the presupposition of a possible subsequent event $\mathrm{z}_{k^{\prime}}$. This turns e into an eventuality that meets exactly the

32 This is not quite correct as an account of the mass-interpretation available for nouns like chicken, lamb, egg, etc. The mass noun property is rather a consequence of construing chicken by what has been called conceptual shift in the sense of meat from chicken. This concept is then already subject to the condition (71). What is to be noted here is merely, that (71) is not an ad-hoc stipulation.

33 Technically, (71) combines with (70)(a) by functional composition, with $\lambda \mathrm{P}$ being saturated by the predicate $\lambda \mathrm{e}\left[\mathrm{e}:\left[\right.\right.$ BECOME $\left[[\right.$ VERT x $\left.\left.\left.] \geq\left[\mathrm{v}_{i}+\mathrm{d}_{i}\right]\right]\right]\right]$. Then lambda conversion yields (72), where "e" replaces " $\mathrm{z}$ " and the argument position " $\lambda \mathrm{x}$ " is inherited from (70)(a). 
conditions of a process ${ }^{34}$. The interesting point is that the presupposition automatically triggered by BECOME takes care of the internal ordering among the sub-events collected in $\mathrm{e}^{35}$.

This consideration directly leads to the second possibility to account for of the homogeneity in the process of getting higher (and higher). It consists in the proposal to simply take (70)(c) as it stands, relying on the following consideration. The homogeneity that holds for mass terms, states, and processes alike is usually not explicitly represented in the semantic representation, but taken as an intrinsic characteristic that comes into play if the pertinent properties are at issue. Hence entries like (74) rather than (75) are taken as canonical for the mass- and process-terms water and sleep, respectively:

$\begin{array}{lllll}\text { (74) a. } & \text { /water/ } & {[+\mathrm{N},-\mathrm{V}]} & \lambda \mathrm{z}[\text { WATER } \mathrm{z}] \\ & \text { b. } & \text { /sleep/ } & {[-\mathrm{N},+\mathrm{V}]} & \lambda \mathrm{x} \lambda \mathrm{e}[\mathrm{e}:[\text { SLEEP } \mathrm{x}]] \\ & & & \\ \text { (75) } & \text { a. } & / \text { water/ } & {[+\mathrm{N},-\mathrm{V}]} & \lambda \mathrm{z}\left[\forall \mathrm{z}_{j}\left[\mathrm{z}_{j} \subseteq \mathrm{z}\right][\text { WATER } \mathrm{z}]\right] \\ & \text { b. } & / \text { sleep } / & {[-\mathrm{N},+\mathrm{V}]} & \lambda \mathrm{x} \lambda \mathrm{e}\left[\forall \mathrm{z}_{j}\left[\mathrm{z}_{j} \subseteq \mathrm{e}\right]\left[\mathrm{z}_{j}:[\text { SLEEP } \mathrm{x}]\right]\right.\end{array}$

The conditions made explicit in (75) do in fact hold in (74): They are inherent conditions of the predicates WATER and SLEEP, respectively. ${ }^{36}$ We might, in the same sense, suppose that the process character of getting higher is a matter of the predicate applying to e in (70), where the condition by which it differs from the (elliptical) event interpretation in (68) is just the variable " $\mathrm{v}_{i}$ " which is not bound by an (implicit) discourse referent, as the "v" in (68), but related to a previous state of $\mathrm{x}$, such that no event-external target state gets defined. Viewed in this way, the property defined in (70) is inherently a process, just like the properties defined by SLEEP or MOVE are inherently processes. In other words, the event represented in (68) and the process represented in (70) differ just as much as a lamb and lamb - or whisky and a whisky, for that matter - , the difference formally represented by the discourse referent $\underline{\mathrm{v}}$ in (68) and the unbound parameter $\mathrm{v}_{i}$ with the value of $\mathrm{d}_{i}$ depending on it in (70).

${ }^{34}$ It has sometimes been objected, e.g. in Steinitz (1998), against this line of reasoning that processes like getting higher are not sequences of events but rather continuous changes. In a similar vein, Steinitz argues, Jackendoff (1996) rejects the view that motion can be characterized by a finite set of subevents. "A finite sequence of subevents necessarily has as specified beginning and ending, so it cannot encode the absence of endpoints." (p.316). The misunderstanding comes from assuming a finite sequence of subevents. The collection of subevents relied on in (71) is neither discrete nor finite, just like conceptually an amount of water is neither a discrete nor a finite set of sub-quantities of water. What the condition in (71) expresses is merely the requirement that whatever $\mathrm{z}_{k}$ might be chosen, it has the same property as $\mathrm{z}$ and any other part of it. This is exactly what Bach (1986) assumes for processes.

35 It might be noted that the optional adverbial immer in German and the optional repetition of the comparative higher and higher in English and German indicate somehow the iteration introduced by (71). Although this looks plausible in principle and might be correct etymologically, it is not an effect of compositional interpretation and has to be left as a remark of plausibility.

36 There are in fact templates having the inverse effect of the "grinder" (71) deriving count nouns like two beer or more than one whisky with different ways to support the individuation. Note also the comments in footnote 32 on shifted count nouns. 
This gets us to the second problem to be clarified with respect to (70), namely the source and the status of the value $\mathrm{v}_{i}$ as well as $\mathrm{d}_{i}$, which need to be treated separately. As to $\mathrm{v}_{i}$, a straightforward way to clarify the issue seems to be the assumption that the position " $\lambda \mathrm{v}$ " of the comparative is removed from the argument structure in entries like (65), leaving " $v$ " as a parameter, for which " $\mathrm{v}_{i}$ " is just a notational variant to make its character explicit. By this assumption, (70) would not be elliptical, as (68) indeed is, and it ceases to represent an event that ends with a distinct target state. This sort of reasoning, however, runs into serious difficulties: Even though there are different proposals as to how the comparative is to be represented, there is clear consensus that relating to an entity to be compared with is the distinguished property of comparatives. In terms of the analysis assumed here, it is the very position " $\lambda \mathrm{v}$ " in (65) that represents this property. Hence removing it from the entry of the comparative deprives the comparative from its core characteristic. Moreover, the notational contrast between " $\mathrm{v}_{i}$ " and " $\mathrm{v}$ " is not just a hint to the reader but has systematic consequences, since " $\mathrm{v}_{i}$ " is not available for the values 0 and $\mathrm{N}$, the options for " $\mathrm{v}$ " in the positive. Hence " $\mathrm{v}_{i}$ " (or whatever notation one might choose) must have a systematic status by its own. In short, then, " $v_{i}$ " must be different from " $v$ ", presumably related to the comparative morpheme in one way or the other, and it is not available for binding by an argument position or an (implicit) discourse referent. For the time being, I will leave it at that, briefly returning to the problem below. ${ }^{37}$ I will assume, however, that eventually an account should be available which reduces this problem to independently motivated assumptions. Although the status of $d_{i}$ requires an account by its own, it is clearly not independent of $v_{i}$, hence I will not make an ad hoc proposal for this element either.

To sum up the considerations about the contrast illustrated in (60) and (61): If BECOME combines with a comparative not providing a value of comparison, the result denotes a process rather than an event. The reason is the lack of a proper target state: The property of $\mathrm{x}$ defined by $[[\mathrm{DIM} \mathrm{x}] \geq$ $\left.\left[\mathrm{v}_{i}+\mathrm{d}_{i}\right]\right]$ - where [ DIM $\left.\mathrm{x}\right]$ stands for any dimensional characteristic of $\mathrm{x}-$ is only fixed with respect to the change-internal value $\mathrm{v}_{i}$. In this sense, the parameter $\mathrm{v}_{i}$ turns the event marked by BECOME into a continuous process, where the presupposition provided by (34') is restricted in a way which guarantees the coherence between the parts of the process, providing each potential stage with its presupposed predecessor. As a side-effect, the collection of values for " $\mathrm{d}_{i}$ " maps the growths (or reduction) of [DIM $\mathrm{x}]$ onto parts of the time interval of e, whatever partitioning of the process e is considered.

Additional motivation for this analysis comes from the fact that verbs like fall, rise, grow, increase, reduce, change and quite a few others, denoting transition processes which FabriciusHansen (2001) calls counterdirectional, can most naturally be construed as incorporating comparative constructions of the sort just discussed, as examples like (76) and their close synonyms (77) show:

(76) a. The price of gas rises.

b. Later on, the interest rate fell.

c. His debts increased.

d. The tree grew, but only slowly.

37 See footnote 39 . 
(77) a. The price of gas becomes higher.

b. Later on, the interest rate got lower.

c. His debts became larger.

d. The tree became taller, but only slowly.

Assuming that fall and rise indicate movements on a vertical scale, the entry for rise can be given as $(78)^{38}$.

$$
\text { /rise/ } \quad[+\mathrm{V},-\mathrm{N}] \quad \lambda \mathrm{x} \lambda \mathrm{e}\left[\mathrm{e}:\left[\text { BECOME }\left[[\operatorname{VERT} \mathrm{x}] \geq\left[\mathrm{v}_{i}+\mathrm{d}_{i}\right]\right]\right]\right]
$$

This entry triggers a presupposition in much the same way in which (70)(a) fosters the presupposition spelled out in $(70)(\mathrm{c})$. There is one non-trivial point to be added here, however. (78) is intended to account for cases like (76)(a), which do not come with a specification of the amount of rising. But such a specification is possible, as shown in (79):

(79) a. The price of gas rises at least ten cent.

b. The river has risen two feet.

Cases like these require two amendments. First, like dimensional adjectives and their comparatives - see (62) and (65), respectively - rise and fall admit an optional argument position, by which the value of "d" can syntactically be specified by a Measure Phrase. This leads to the following modification of (78):

$$
\text { /rise/ } \quad[+\mathrm{V},-\mathrm{N}] \quad(\lambda \mathrm{d}) \lambda \mathrm{x} \lambda \mathrm{e}[\mathrm{e}:[\operatorname{BECOME}[[\operatorname{VERT} \mathrm{x}] \geq[\mathrm{v}+\mathrm{d}]]]]
$$

Second, in order to accommodate a specification of "d" made possible by (80), "v" must provide a value this specification can be added to (or subtracted from). This is - according to the assumptions made above - an automatic consequence of replacing " $\mathrm{d}_{i}$," which is completely dependent on the occurrence of " $v_{i}$ ", by the variable " $d$ ", which is bound by the argument position " $\lambda \mathrm{d}$ ". The value of " $v$ " can only be 0 or some contextually specified amount to compare with. In cases like (79), this must be due to some discourse referent $\underline{\mathrm{v}}$ taken from the previous context. In other words, it must not be a "process-internal" value " $\mathrm{v}_{i}$ ", but rather an externally given target $\underline{\mathrm{v}}$. For this reason, I have switched back in (80) to " $\mathrm{v}$ " instead of " $\mathrm{v}_{i}$ ", supposing that " $\mathrm{v}$ ", if it is not bound by some discourse referent $\underline{\mathrm{v}}$, allows for the value $0, \mathrm{~N}$, or $\mathrm{v}_{i}$, depending on general conditions of semantic interpretation. ${ }^{39}$ With this proviso, the VP of (79)(b) will be something like (81):

${ }^{38}$ It might be noted that I ignore here (and throughout) the alternation between vertical extension and vertical position. As a matter of fact, high is ambiguous between extension and position in high window, while high position is restricted to location, and high mountain to extension. In the same way, rise alternates between position in the sun rises and extension in the river rises and is presumably ambiguous in the ground rises. Hence VERT is underspecified in this respect, sensitive to conditions not to be explored here.

39 Two points of the otherwise fairly complex conditions should be sorted out here. First, $\mathrm{v}_{i}$ must now be considered as one of the values available for " $\mathrm{v}$ ", if " $\mathrm{v}$ " is not bound by the argument position " $\lambda \mathrm{v}$ ". 


$$
\text { /rise two feet/ }[+\mathrm{V},-\mathrm{N}] \quad \lambda \mathrm{x} \lambda \mathrm{e}[\underline{\mathrm{v}} \mid \mathrm{e}:[\operatorname{BECOME}[[\operatorname{Vert} \mathrm{x}] \geq[\mathrm{v}+2 \text { FEet }]]]]
$$

One might observe, incidentally, that the presupposition "s: $\neg[$ [VERT $\mathrm{x}] \geq[\mathrm{v}+2$ FEET $]$ ]", which (34') triggers in (81), is implied by the narrower condition "s: [[VERT x] = v]". Notice, moreover, that rise as a lexical entry with the optional argument " $\lambda \mathrm{d}$ " is parallel to its close synonym become higher as discussed with respect to (60)(c), the two readings of which are made explicit in (76) vs. (78). One consequence of an explicit value assigned to "d" is that e.g. rise two feet is an event (or more specifically an accomplishment according to the Vendler-terminology), and not a process, since only the final part of the event satisfies the condition of rising two feet, much like became two feet higher or became higher than six feet. ${ }^{40}$

To summarize these considerations: the occurrence of " $v_{i}$ " (or whatever represents the process character of rise, become higher, etc.) is incompatible with the assignment of process-external values to either " $\mathrm{v}$ " or "d". In this sense, $\mathrm{v}_{i}$ and $\mathrm{d}_{i}$ warrant the homogeneity of the continuous change expressed by rise, fall, and their equivalents.

\section{The Interaction of BECOME and AGAIN}

A final consideration will take up one of the issues repeatedly discussed with respect to BECOME and illustrated by the ambiguity of cases like (82):

At six the shop closed again.

Under the so-called restitutive reading, (82) presupposes that the shop was closed before the event in question, under the repetitive reading, it presupposes a previous event of closing, hence a second period of the shop's being open. The restitutive reading is preferred, under nuclear stress on close, while nuclear stress on again forces the repetitive reading. The standard analysis relates this difference in one way or the other to the scope of the particle again ${ }^{41}$ Thus adding the particle again to a VP like close in (82) introduces the presupposition that either the event as a whole (repetitive) or merely the state resulting from it (restitutive) occurred already before. The semantics of again must therefore proliferate the semantic structure $\phi$ of the constituent it combines with, adding the presupposition that $\phi$ or the result of $\phi$ occurred before. In order to

Second, for the value $\mathrm{v}_{i}$ to show up, the variable "d" must not be assigned any specific value. In other words, if "d" is specified by a measure phrase or any other complement, "v" cannot be construed as $\mathrm{v}_{i}$. For discussion of the conditions governing the choice of 0 and $\mathrm{N}$ for "v", see Bierwisch (1989).

40 Notice that the discourse referent $\underline{\mathrm{v}}$ in (81) binds also the variable " $\mathrm{v}$ " in the presupposition generated by BECOME, as shown in (i):

(i) /rise two feet/ $[+\mathrm{V},-\mathrm{N}]$

$\lambda \mathrm{x} \lambda \mathrm{e}[\underline{\mathrm{v}} \mid\{\mathrm{s} \bigcirc \mathrm{e} \& \mathrm{~s}: \neg[[\operatorname{Vert} \mathrm{x}] \geq[\mathrm{v}+2$ FeEt $]]\}[\mathrm{e}:[$ Become $[[\operatorname{Vert} \mathrm{x}] \geq[\mathrm{v}+2$ FeEt $]]]]]$

41 For an overview of the various attempts to account for these phenomena see the references given in footnote 7, and also Bierwisch (2000), and Fabricius-Hansen (2001). The following discussion will be restricted to the semantic effect that again has on expressions with BECOME. I must refrain from dealing with problems of nuclear stress, position of again, and the dependencies among them. 
capture this alternation, I will define an operator RES that suppresses the transition, retaining merely the eventual resulting state:

$$
\mathrm{s}:[\operatorname{RES}[\operatorname{BECOME} \mathrm{p}]]=_{\operatorname{def}}[\mathrm{s}: \mathrm{p}]
$$

By means of this operator, we can express the two readings induced by again by the entry (84), where the categorization [Part] is completely provisional, indicating that again is a particle adjoined to a $[+\mathrm{V}]$-constituent of as its syntactic head:

$$
\begin{aligned}
& \text { lagain/ } \quad[\text { Part }] \quad \lambda \mathrm{P} \lambda \mathrm{x} \lambda \mathrm{e}\left[\left(\exists \mathrm{e}^{\prime}\right)\left\{\mathrm{e}^{\prime}<\mathrm{e} \& \mathrm{e}^{\prime}:(\mathrm{RES})[\mathrm{P} \mathrm{x}]\right\} \text { e: }[\mathrm{P} \mathrm{x}]\right] \\
& {[+\mathrm{V}]}
\end{aligned}
$$

The condition " $\mathrm{e}$ ' $<\mathrm{e}$ " indicates that the event $\mathrm{e}^{\prime}$ and hence its result precedes e. The optionality of RES accounts for the two readings of again: If RES shows up, we get the restitutive case, if it is dropped, we get the repetitive reading. ${ }^{42}$ Applying the two variants of this entry to the intransitive verb close in (85) - the straightforward antonym of open in (33) with the BECOME-presupposition supplied - yields (86) for the restitutive and (87) for the repetitive reading, respectively. Let us first look at (86), where RES picks out the target state $\neg[$ OPEN x ] and adds it to the presupposition component, fixing it as preceding the event e. As the state $\mathrm{s}$ : [ OPEN $\mathrm{x}$ ] induced by BECOME and $s^{\prime}: \neg[$ OPEN $\mathrm{x}]$ induced by again cannot be simultaneous, the letter can only precede the former:

$$
\begin{aligned}
& \text { /close/ }[+\mathrm{V},-\mathrm{N}] \quad \lambda \mathrm{x} \lambda \mathrm{e}\left[\left(\exists \mathrm{s}^{\prime}\right)\{\mathrm{s} \bigcirc \mathrm{e} \& \mathrm{~s}:[\text { OPEN } \mathrm{x}]\} \text { e: }[\text { BECOME } \neg[\text { OPEN x }]]\right] \\
& \text { /close again/ } \quad[+\mathrm{V},-\mathrm{N}] \quad \lambda \mathrm{x} \lambda \mathrm{e}\left[\left\{\mathrm{s}^{\prime}<\mathrm{e} \& \mathrm{~s} \bigcirc \mathrm{e} \& \mathrm{~s}^{\prime}: \neg[\text { OPEN x }] \& \mathrm{~s}:[\text { OPEN x }]\right]\right\} \\
& \mathrm{e}:[\text { BECOME } \neg[\text { OPEN x }]]]
\end{aligned}
$$

Turning to the repetitive reading, we notice that first again adds the complete previous event $\mathrm{e}^{\prime}:$ [BECOME $\neg[$ OPEN $\left.\mathrm{x}]\right]$ to the presupposition component, which then triggers its own presupposition, indicating that $\mathrm{e}^{\prime}$ also starts with the condition $\mathrm{s}^{\prime}$ : $[\mathrm{OPEN} \mathrm{x}]$ :

$$
\begin{aligned}
& \text { /close again/ }[+\mathrm{V},-\mathrm{N}] \\
& \lambda \mathrm{x} \lambda \mathrm{e}\left[( \exists \mathrm { e } ^ { \prime } ) ( \exists \mathrm { s } ^ { \prime } ) \left\{\mathrm{e}^{\prime}<\mathrm{e} \& \mathrm{~s}^{\prime} \bigcirc \mathrm{e}^{\prime} \& \mathrm{~s} \bigcirc \text { e } \& \mathrm{~s}^{\prime}:[\text { OPEN x }] \& \mathrm{e}^{\prime}:[\text { BECOME } \neg[\text { OPEN x }]] \&\right.\right. \\
& \text { s: }[\text { OPPEN x }]]\} \\
& \mathrm{e}:[\text { BECOME } \neg[\text { OPEN x }]]]
\end{aligned}
$$

42 This optionality is not the correct solution, though, as the restitutive reading is restricted to again without nuclear stress, which is again restricted syntactically. A first step to account for these additional conditions might be expressed as in (i), using the index-mechanism mentioned earlier:

(i) /again/ [Part, $\alpha$ Focus $] \lambda \mathrm{P} \lambda \mathrm{x} \lambda \mathrm{e}\left[\left(\exists \mathrm{e}^{\prime}\right)\left\{\mathrm{e}^{\prime}<\mathrm{e} \& \mathrm{e}^{\prime}:\left({ }_{b}\right.\right.\right.$ RES $\left.)[\mathrm{P} \mathrm{x}]\right\}$ e: $\left.[\mathrm{P} \mathrm{x}]\right]$

$[+\mathrm{V}]$

Condition: $\alpha=$ plus implies $\mathrm{b}=$ minus

This is only a first approximation for reasons mentioned in note 41. In particular, (i) does not spell out the syntactic and prosodic properties connected to $[ \pm$ Focus], regulating stress and surface position. 
Notice that the correct sequence of states OPEN $\rightarrow \neg$ OPEN $\rightarrow$ OPEN $\rightarrow \neg$ OPEN with the first three states belonging to the presupposition, while the last one marks the eventual result, automatically derives from the entries for again and close plus the template (34').

Let us finally turn to the intricate cases of BECOME that alternate between event and process. For the sake of illustration, I will restrict the discussion to the cases in (88), where underscoring indicates focus stress:

(88) a. The river rises slowly.

b. The river has risen two feet.

c. The river has risen two feet again.

d. The river has risen two feet again. / Again the river has risen two feet.

e. The river rises again.

f. The river rises again. / Again the river is rising.

To begin with, (88)(a) allows for an event- and a process-reading, as already discussed. For the sake of reference, 1 repeat as (89) the entry given in (80), supplied with the presupposition induced by ВЕСОмЕ, from which rise two feet derives as already shown in (81), where the process reading is blocked by the specification of $\mathrm{d}$, which requires $\mathrm{v}$ to be contextually specified, as indicated by the discourse referent $\underline{\mathrm{v}}$ :

$$
\begin{aligned}
& \text { /rise/ }[+\mathrm{V},-\mathrm{N}] \\
& (\lambda \mathrm{d}) \lambda \mathrm{x} \lambda \mathrm{e}[\{\mathrm{s} \bigcirc \mathrm{e} \& \mathrm{~s}: \neg[[\operatorname{Vert~x}] \geq[\mathrm{v}+\mathrm{d}]]\} \text { e: }[\text { BeCOMe }[[\operatorname{verT} \mathrm{x}] \geq[\mathrm{v}+\mathrm{d}]]]]
\end{aligned}
$$

$$
\text { /rise two feet/ } \quad[+\mathrm{V},-\mathrm{N}]
$$

( $\lambda \mathrm{d}) \lambda \mathrm{x} \lambda \mathrm{e}[\underline{\mathrm{v}}\{\mathrm{s} \bigcirc \mathrm{e} \& \mathrm{~s}: \neg[[\operatorname{vert} \mathrm{x}] \geq[\mathrm{v}+2 \mathrm{FEET}]]\}$ e: $[$ BeCOME $[[\operatorname{Vert} \mathrm{x}] \geq[\mathrm{v}+2 \mathrm{FEET}]]]]$

If this is combined with again, we get the two readings, as expected. Intuitively, the preferred interpretation of (88)(c) indicates the restitution of an earlier sate, where the river had a height that has now been reached again through rising by two feet. Formally, that comes out as (90), an automatic consequence of combining again with (81):

$$
\begin{aligned}
& \text { /rise two feet again/ } \quad[+\mathrm{V},-\mathrm{N}] \\
& \lambda \mathrm{x} \lambda \mathrm{e}\left[\underline{\mathrm{v}} \mid\left(\exists \mathrm{s}^{\prime}\right)\left\{\mathrm{s}^{\prime}<\mathrm{e} \& \mathrm{~s} \bigcirc \mathrm{e} \& \mathrm{~s}:[[\text { VERT x }] \geq[\mathrm{v}+2 \text { FEET }]] \& \mathrm{~s}: \neg[[\text { VERT } \mathrm{x}] \geq[\mathrm{v}+\right.\right. \\
& 2 \text { FEET }]]\} \text { e: }[\text { BECOME }[[\text { VERT } \mathrm{x}] \geq[\mathrm{v}+2 \text { FEET }]]]]
\end{aligned}
$$

Notice that, much like for restitutive open again represented in (86), three states are identified: the presupposed height of $\mathrm{v}+2$, picked out by the result-operator RES of again, then less than $\mathrm{v}+2$, presupposed by ВеСОмE, and finally the target $\mathrm{v}+2$, all with respect to a contextually fixed value $\underline{\mathrm{v}}$ of " $\mathrm{v}$ ". 
Looking next at the repetitive interpretation, which is the only possibility for $(88)(d)^{43}$, where no RES reduces the presupposition of again to the previous occurrence of the target state, we get (91), with four successive state, as in (87) for close again, with necessarily two values $\mathrm{v}$ and $\mathrm{v}^{\prime}$ to be compared with. ${ }^{44}$

$$
\begin{aligned}
& \text { /rise two feet again/ } \quad[+\mathrm{V},-\mathrm{N}] \\
& \lambda \mathrm{x} \lambda \mathrm{e}\left[\underline{\mathrm{v}}, \mathrm{v}^{\prime} \mid\left(\exists \mathrm{e}^{\prime}\right)\left(\exists \mathrm{s}^{\prime}\right)\left\{\mathrm{e}^{\prime}<\mathrm{e} \& \mathrm{~s}^{\prime} \bigcirc \mathrm{e}^{\prime} \& \mathrm{~s} \bigcirc \mathrm{e} \& \mathrm{~s}^{\prime}: \neg\left[[\text { VERT } \mathrm{x}] \geq\left[\mathrm{v}^{\prime}+2 \text { FEET }\right]\right] \&\right.\right. \\
& \left.\mathrm{e}^{\prime}:\left[\text { BECOME }\left[[\text { VERT } \mathrm{x}] \geq\left[\mathrm{v}^{\prime}+2 \text { FEET }\right]\right]\right] \& \mathrm{~s}: \neg[[\text { VERT } \mathrm{x}] \geq[\mathrm{v}+2 \text { FEET }]]\right\} \text { e: }[\text { BECOME } \\
& [[\text { VERT } \mathrm{x}] \geq[\mathrm{v}+2 \text { FEET }]]]]
\end{aligned}
$$

What $(88)(d)$ expresses, does not necessarily mean that the two events add up to the rivers rising by four feet. As a matter of fact, e and $\mathrm{e}^{\prime}$ are independent of each other, with falling or rising or not changing water in between.

Let us finally turn to the processes in (88)(e) and (f), where once again (88)(f) unambiguously denotes a repeated process, i.e. it asserts a process of rising, and it presupposes a previous process of the same type. Relying on the process reading of rise given in (78) with the presupposition added, we get (92) as the effect of combining it with repetitive again, i.e. the reading without the RES-operator:

$$
\begin{aligned}
& \text { /rise again/ } \quad[+\mathrm{V},-\mathrm{N}] \\
& \lambda \mathrm{x} \lambda \mathrm{e}\left[( \exists \mathrm { e } ^ { \prime } ) ( \exists \mathrm { s } ^ { \prime } ) \left\{\mathrm{e}^{\prime}<\mathrm{e} \& \mathrm{~s}^{\prime} \bigcirc \mathrm{e}^{\prime} \& \mathrm{~s} \bigcirc \mathrm{e} \& \mathrm{~s}^{\prime}:\left[[\text { VERT } \mathrm{x}]=\mathrm{v}_{i}^{\prime}\right] \& \mathrm{e}^{\prime}:[\text { BECOME [[VERT }\right.\right. \\
& \left.\left.\left.\left.\mathrm{x}] \geq\left[\mathrm{v}_{i}^{\prime}+\mathrm{d}_{i}\right]\right]\right] \& \mathrm{~s}:\left[[\text { VERT } \mathrm{x}]=\mathrm{v}_{i}\right]\right\}[\mathrm{e}:[\text { BECOME }[[\text { VERT } \mathrm{x}] \geq[\mathrm{v}+\mathrm{d}]]]]\right]
\end{aligned}
$$

As required, we get two independent processes, with the water rising, falling or simply not changing in between.

The most intriguing case is (88)(e), which has readings that are compatible with at least the following conditions:

(93) a. The river rises again, after it didn't change for a while.

b. The river rises again, after it was going down before.

In (93)(a), the presupposition triggered by again is most naturally met by a previous process of rising, followed by an interval with no increase of water. This means that (93)(a) is an instance

43 Whether the repetitive interpretation is also available for $(88)(\mathrm{c})$, can be left open here. Clearly the restitutive reading is preferred for (c) and definitely blocked for (d).

44 Taking the more restricted presupposition discussed above as a kind of default interpretation for comparative-like representations, we get (i) with a more perspicuous sequence of the four states in question:

(i) $\lambda \mathrm{x} \lambda \mathrm{e}\left[\underline{\mathrm{v}}, \underline{\mathrm{v}}^{\prime} \mid\left(\exists \mathrm{e}^{\prime}\right)\left(\exists \mathrm{s}^{\prime}\right)\left\{\mathrm{e}^{\prime}<\mathrm{e} \& \mathrm{~s}^{\prime} \bigcirc \mathrm{e}^{\prime} \& \mathrm{~s} \bigcirc \mathrm{e} \&\right.\right.$

$\mathrm{s}^{\prime}:\left[[\operatorname{VERT} \mathrm{x}]=\mathrm{v}^{\prime}\right] \& \mathrm{e}^{\prime}:\left[\right.$ BeCOME $\left[[\operatorname{VERT} \mathrm{x}] \geq\left[\mathrm{v}^{\prime}+2\right.\right.$ FEET $\left.\left.\left.]\right]\right] \& \mathrm{~s}:[[\operatorname{VERT} \mathrm{x}]=\mathrm{v}]\right\}[\mathrm{e}:[$ BeCOME $[[\operatorname{VERT} \mathrm{x}] \leq[\mathrm{v}+2$ FEET $]]]]]$ 
of repetitive interpretation of again. In other words, the VP rise again in (93)(a) must be that already spelled out in (92). A less prevalent reading of (93)(a) might however be compatible with a situation where the steady period was preceded by the river's going down. This would be a reading that is explicitly required in (93)(a) and must hence be accounted for anyway, even though it cannot be represented in (92), which relies on the repetitive again. As a matter of fact, the presupposition of this reading must be compatible with the inverse process required by repetitive again, as explicitly stated in (93)(b). The presupposition that (88)(e) requires independently of the conditions added in (93) could presumably be paraphrased most plausibly as it was already higher before. This seems to be the minimal condition in order to justify the requirement of again - something that could be repeated in the process of rising, but still compatible with various conditions in between, such as rising, falling, or steady height of waters, except that some falling is logically necessary. Otherwise the river cannot get back from the earlier height. Could this condition be derived by means of the restitutive reading of again? (94) shows the VP resulting from this possibility:

$$
\begin{aligned}
& \text { /rise again/ } \quad[+\mathrm{V},-\mathrm{N}] \\
& \lambda \mathrm{x} \lambda \mathrm{e}\left[\left(\exists \mathrm{s}^{\prime}\right)\left\{\mathrm{s}^{\prime}<\mathrm{e} \& \mathrm{~s} \bigcirc \mathrm{e} \& \mathrm{~s}^{\prime}:\left[[\text { VERT } \mathrm{x}] \geq\left[\mathrm{v}_{i}+\mathrm{d}_{i}\right]\right] \& \mathrm{~s}:\left[[\operatorname{VERT} \mathrm{x}]=\mathrm{v}_{i}\right]\right]\right\}[\mathrm{e}:[\text { BeCOME } \\
& \left.\left.\left.\left[[\operatorname{VERT} \mathrm{x}] \geq\left[\mathrm{v}_{i}+\mathrm{d}_{i}\right]\right]\right]\right]\right]
\end{aligned}
$$

What we've got here is the specification of a target and two presupposed states, just as in (90) for rise two feet again. The presupposition $\mathrm{s}^{\prime}$ : [[VERT $\left.\left.\mathrm{x}\right] \geq\left[\mathrm{v}_{i}+\mathrm{d}_{i}\right]\right]$ is the automatic result of applying the restitutive reading of again, and especially its operator RES, to the process reading [e: [BECOME [[VERT $\left.\left.\left.\mathrm{x}] \geq\left[\mathrm{v}_{i}+\mathrm{d}_{i}\right]\right]\right]\right]$ of rise, which in turn triggers the second presupposition s: [[VERT $\left.\left.\mathrm{x}]=\mathrm{v}_{i}\right]\right]$. Differing from (90), however, the target state as well as the presupposed $\mathrm{s}$ : [[VERT $\left.\mathrm{x}]=\mathrm{v}_{i}\right]$ in (94) are not states external to the process, but by definition part of and dependent on the process, exactly as in (70)(c) for become higher. Now, this comment applies equally to the presupposed state that again computes from the target of the process: It is not a proper, external state that gets repeated, but a process-internal target. But whatever value one might chose for $\mathrm{v}_{i}$, it is surpassed by the presupposition $\mathrm{v}_{i}+\mathrm{d}_{i}$. Hence before the presupposition that initiates the actual rising is met, the inverse process must take place, which makes (94) compatible with the condition spelled out in (93)(b).

It seems that this analysis accounts neatly for the apparently vague intuition about the interpretation of (80)(e) The river rises again, which doesn't seem to be restitutive in a clear sense at first glance, as it does not presuppose a definite state nor a process to return to. But it presupposes a state holding before the actual rising of the river and correctly described by a bare comparative. This however is precisely what the restitutive reading of again applied to the process reading of "counterdirectionals" predicts. If this is correct, it supports the various assumptions introduced independently in a non-trivial way.

The analysis furthermore seems to extend as expected to a wide range of related phenomena. Thus comparatives with BECOME create the same process readings, even if they are not originally dimensional, as in Things became better every day, the road got bumpier (and bumpier), the 
situation got more (and more) out of control, the weather became less friendly again ${ }^{45}$. Similarly for other verbs "incorporating" BECOME plus comparative as in the colors gradually faded in the sun, the road widened again, (due to the rain) slowly the grass grew again.

\section{Loose Ends}

Although the properties of BECOME have been explored extensively in various frameworks, it is still worthwhile to take a closer look at its presuppositional structure. For one thing, even though the change to a target state starting from a source that implies the negation of the target is certainly a definitional condition of BECOME, it is not a triviality that the source state is a presupposition. It is one of the consequences of this fact, that in the very common cases of caused change as in kill, clean, and the causative variants of all ergative verbs like break, open, etc. it is the BECOMEcomponent, rather than the causative operator CAUSE, that triggers the presupposition. This is borne out, among other things, by the fact that causative verbs without the BECOME-component, like turn as in the engine turned the wheel steadily do not have a presupposition of the relevant type.

Interesting consequences of the presupposition triggered by BECOME show up if BECOME interacts with other elements affecting the relevant conditions. The two cases we have explored in more detail are the different effects of comparatives and the alternative readings of again, the semantic contribution of which consists in nothing but an additional presupposition. While the relevant representations have been spelled out in relevant detail, their systematic computation is in need of further clarification in at least three respects.

The first concerns the nature of implicit values of comparison, which show up in comparatives and result in the process character in combination with BECOME. Notationally, " $v_{i}$ " is intended to express the process-internal specification of the value, but so far there is no independent mechanism to specify and interpret the value. The stipulation seems to provide what is necessary. What we do want, however, is a way to relate this stipulation to a more general account of values for hidden variables. What comes to mind is the regime for implicit variables of complex tenses or the conditions regulating deictic specifications in locative prepositions. But this is merely a loose association with no substantive content to rely on.

To this problem, the second aspect in need of clarification is related. It concerns the way in which the standard presupposition triggered by BECOME is restricted to the special condition [DIM $\mathrm{x}=\mathrm{v}_{i}$ ] instead of the more general [DIM $\mathrm{x}<\mathrm{v}_{i}+\mathrm{d}_{i}$ ]. While it is always possible to satisfy a presupposition by a more specific condition, the restriction in this case should be available for independent motivation. This motivation has to cope with the special status of $\mathrm{d}_{i}$, by which DIM $\mathrm{x}$ differs from $\mathrm{v}_{i}$. Intuitively, the value of " $\mathrm{d}_{i}$ " increases from 0 during each of the sub-eventualities that can be chosen from the process in question, although no change of $\mathrm{d}_{i}$ needs to be explicitly

45 For some discussion of comparatives based on evaluative and other non-dimensional adjectives see Bierwisch (1989), where it is claimed that the comparative of a non-dimensional predication [P x] introduces a template $\mathrm{Q}$, such that $\mathrm{Q}[\mathrm{P} \mathrm{x}]$ maps $\mathrm{x}$ wrt. $\mathrm{P}$ on a scale of comparison. Technicalities are to be left aside here. 
represented. Here too, more general mechanisms, rather than an appropriate stipulation, should eventually explain the source of the representations that seem to be intuitively correct.

Finally, I have considered again as lexically ambiguous between a restitutive reading with the operator RES and a repetitive reading without $\mathrm{it}^{46}$. RES is intrinsically related to BECOME, distinguishing between two types of presupposition. ${ }^{47}$ What needs clarification, as already mentioned in footnote 42 , is the way in which the choice between repetitive and restitutive interpretation is related to the location of nuclear stress and the possible syntactic position of the particle. Similar, albeit different relations show up with particles like also and still. Whether these different conditions and effects can be reduced to general mechanisms, remains to be seen.

\section{References}

Bach, Emmon (1986) The Algebra of Events, Linguistics and Philosophy 9, 1-16

Bierwisch, Manfred (1989) The Semantics of Gradation, in: Manfred Bierwisch and Ewald Lang (eds.) Dimensional Adjectives, 71-261, Berlin: Springer-Verlag

Bierwisch, Manfred (1990) Event Nominalization: Proposals and Problems, Acta Linguistica Hungarica 40, 19-84

Bierwisch, Manfred (1997) Lexical Information from a Minimalist Point of View, in: Christopher Wilder, Hans-Martin Gärtner, Manfred Bierwisch (eds.) The Role of Economy Principles in Linguistic Theory, 227-266, Berlin: Akademie-Verlag

Bierwisch, Manfred (2000) Wieder-Gänger, in: Johannes Dölling and Thomas Pechmann (eds.) Prosodie, Struktur, Interpretation, Linguistische Arbeitsberichte 74, 67-82, Leipzig: Institut für Linguistik, Universität Leipzig

Bierwisch, Manfred (2002) A Case for CAUSE, in: Ingrid Kaufmann and Barbara Stiebels (eds.) More than Words, 299-325, Berlin: Akademie Verlag

Bierwisch, Manfred and Ewald Lang (1989) Dimensional Adjectives, Berlin: Springer-Verlag

Chomsky, Noam and Morris Halle (1968) The Sound Pattern of English, New York: Harper and Row,

46 It has been argued by Dowty (1979), and more recently by von Stechow (1996), that the alternative interpretation of again can be reduced to one lexical reading, the difference being due to again having scope over BECOME or only the resulting state, the latter corresponding to the effect of RES. There are various problems with this proposal, however, some of which are discussed in Kamp and Roßdeutscher (1994), and Bierwisch (2000).

47 It must be added that the distinction between the two readings of again show up also if no BECOME is involved, as in he was sick again (repetitive) vs. he was sick again ("restitutive"), where the interval between the earlier state and its restitution must be warranted in a different way. For further discussion, which must be left aside here, see Bierwisch (2000). It might be noted, though, that the two readings are subject to the same conditions that also govern the choice between repetition and restitution in the context of BECOME. 
Dowty, David (1979) Word Meaning and Montague Grammar, Dordrecht: Reidel

Fabricius-Hansen, Cathrine (2001) "Wi(e)der" and "Again(st)", in: Caroline Fery, Wolfgang Sternefeld (eds.) Audiatur Vox Sapientiiae, 101-130, Berlin: Akademie Verlag

Haegeman, Liliane (1985) The GET-passive and Burzio's generalization, Lingua 66, 53-77

Higginbotham, James (1985) On Semantics, Linguistic Inquiry 16, 547-593

Jackendoff, Ray S. (1996) The Proper Treatment of Measuring Out, Telicity, and perhaps even Quantification in English, Natural Language and Linguistic Theory 14, 305-354

Kamp, Hans (2001) The importance of Presupposition, in: Christian Rohrer, Antje Roßdeutscher, Hans Kamp (eds.) Linguistic Form and its Computation, Stanford: Center for the Study of Language and Information

Kamp, Hans and Uwe Reyle (1993) From Discourse to Logic, Dordrecht: Kluwer Academic Press

Kamp, Hans and Antje Roßdeutscher (1994) Remarks on Lexical Structure and DRS-Construction, Theoretical Linguistics 20, 97-164

Karttunen, Lauri and Stanley Peters (1979) Conventional Implicature, in: Choon -Kyu Oh and David A. Dinneen (eds.) Presupposition, Syntax and Semantics 11, p. 1-56, New York: Academic Press

Kiparsky, Paul and Carol Kiparsky (1970) Fact in: Manfred Bierwisch and Karl-Erich Heidolph (eds.) Progress in Linguistics 143-173, The Hague: Mouton

Wolfgang Klein (1994) Time in Language, London and New York: Routledge

Kratzer, Angelika (1994) The Event Argument and the Semantics of Voice, Ms. Amherst

Maienborn, Claudia (2002) Die logische Form von Kopula-Sätzen, Berlin: Akademie Verlag

Reis, Marga and Inger Rosengren (1997) A Modular Approach to the Grammar of Additive Particles: the Case of German Auch, Jornal of Semantics 14, 237-309

Steinitz, Renate (1999) Die Kopula werden und die Situationstypen, Zeitschrift für Sprachwissenschaft 18, 121-151

von Stechow, Arnim (1984) Comparing Semantic Theories of Comparison, Journal of Semantics 3, p. 1-77

von Stechow, Arnim (1996) The Different Readings of wieder "again": A Structural Account, Journal of Semantics 13, 87-138

Wunderlich, Dieter (1997) Cause and the structure of verbs, Linguistic Inquiry, 28, 27-68

Wunderlich, Dieter (2000) Predicate composition and argument extension as general options, in: Barbara Stiebels, Dieter Wunderlich (eds.) Lexicon in Focus, 247-270, Berlin: Akademie Verlag. 
